\title{
Coletivismo juvenil em Teresina: desenhando um panorama a partir das mídias sociais Instagram e Facebook
}

\author{
Youth collectivism in Teresina: drawing a panorama from social \\ media Instagram and Facebook
}

\section{Colectivismo juvenil en Teresina: dibujando un panorama desde los medios de comunicación sociales Instagram y Facebook}

Recebido em 10-09-2020

Modificado em 21-10-2020

Aceito para publicação em 13-11-2020

\section{Kary Emanuelle Reis Coimbra}

ORCID: 0000-0002-5716-7712

Mestre em Administração pela Universidade Federal de Minas Gerais, linha de pesquisa de Estudos Organizacionais e Sociedade. Doutoranda no Programa de Pós-Graduação em Políticas Públicas da Universidade Federal do Piauí, linha de pesquisa Cultura, Identidade e Processos Sociais. Docente no curso de Administração da Universidade Federal do Piauí. E-mail: karycoimbra@ufpi.edu.br

\section{Maria Dione Carvalho de Morais}

ORCID: 0000-0002-1123-1213

Doutora em Ciências Sociais pela Universidade Estadual de Campinas, com pós-doutorado em Sociologia pela Universidade Federal de Pernambuco. Docente na Universidade Federal do Piauí, no Departamento de Ciências Sociais, e nos Programas de Pós-Graduação em Políticas Públicas (doutorado e mestrado) e de Sociologia (mestrado). E-mail: mdione@uol.com.br

\section{Resumo}

A expansão de coletivos/coletivas juvenis na cidade de Teresina, Piauí, nos anos 2010, levou-nos a indagar sobre sua presença no ciberespaço por meio de mídias sociais e sobre suas pautas de ação política e campos de atuação. Partindo de um levantamento nas mídias sociais Facebook e Instagram, identificamos 27 páginas de coletivos/coletivas, cujas postagens escritas e imagéticas tomamos, metodologicamente em uma abordagem qualitativa de teor interpretativo, como práticas discursivas. Como resultados, constatamos a autodenominação coletivo/coletiva pela quase totalidade dos agrupamentos; o uso de ambas as mídias ou de apenas uma delas; a diversidade de campos de atuação/pautas e suas convergências; os marcadores identitários; e os objetivos, explícitos ou implícitos, de atuação voltada à crítica social, à desconstrução/reconstrução de padrões socioculturais e a projetos emancipatórios.

Palavras-chave: Coletivos e coletivas em Teresina; juventudes; práticas discursivas; mídias sociais. 


\section{Introdução}

No campo de análise das relações entre juventudes e ação política na contemporaneidade, vemos a expressividade - como afirmado por Perez e Silva Filho (2017) - de formações intituladas coletivos/coletivas, em específico, na cidade de Teresina, capital do estado do Piauí, fenômeno que se tornou notório com a expansão desses agrupamentos a partir dos anos 2010. Com foco nesse cenário, objeto de pesquisa de uma tese de doutorado ${ }^{1}$, tratamos, neste artigo, de uma dimensão importante desta ação coletiva: o acionamento das mídias sociais digitais como um dos locus de mobilização/atuação.

Com esse recorte, inspirado pela pesquisa de tese mais ampla, a questão central que mobiliza este texto é: como se dá a presença de coletivos juvenis teresinenses no ciberespaço, mobilizando, por meio de mídias sociais, pautas de ação política em determinados campos de atuação? Buscando responder a tal pergunta, partimos de um levantamento de expressões do coletivismo juvenil na cidade de Teresina, que, embora não restritas à atuação por meio das mídias digitais, têm nelas um importante locus de ação que se soma às atuações nos espaços físicos da cidade. Assim, as mídias sociais de coletivos/coletivas são tomadas como um dos seus cenários de atuação, sobre o qual voltamos a atenção neste artigo. $\mathrm{Na}$ análise e interpretação, buscamos delinear o que consideramos as principais características dos agrupamentos selecionados, como campos $^{2}$ de atuação coletiva, principais mídias sociais acionadas e temáticas que se tornam o foco dessas práticas socioculturais e políticas, compondo pautas e apontando para indicialidades de identidades coletivas juvenis.

Para traçar um panorama dessas consideradas pela literatura especializada como novas formas da ação coletiva, adotamos uma abordagem qualitativa (Poupart et al., 2008; Melucci, 2005), por meio de uma leitura com vistas à identificação e interpretação de práticas discursivas (Spink, 2013) no contexto da cultura visual contemporânea (Eckert; Rocha, 2006),

\footnotetext{
${ }^{1}$ Pesquisa em andamento pelo Programa de Pós-Graduação em Políticas Públicas (PPGPP) da Universidade Federal do Piauí (UFPI), sobre coletivos juvenis na cidades de Teresina, na perspectiva de pedagogias decoloniais em cujo âmbito, para além do recorte abordado neste artigo, há uma pesquisa de campo, com participação/observação direta em eventos promovidos por agrupamentos autodenominados coletivos ou Coletivas, na cidade de Teresina, além da realização de entrevistas individuais e coletivas (Coimbra, 2020).

${ }^{2}$ Em diálogos com a teoria dos campos de Pierre Bourdieu, para referir a certos domínios de concorrência e disputa, na perspectiva relacional de análise das dominações e práticas de um determinado espaço social, como um campo específico no qual se posicionam agentes em disputas (Bourdieu, 1998). Sem ignorar o peso da estrutura social, consideramos que, para além dos limites da reprodução, o conceito de campo aponta para uma teoria da ação dos agentes como intelectuais orgânicos contra-hegemônicos e para possibilidades de subversão dos campos sociais (Montagner; Montanger, 2011).
} 
na qual tecnologias multimídias promovem uma construção hipertextual, o que Chartier (2016:1) denomina “[...] idade da textualidade eletrônica (tradução livre)"3.

As construções hipertextuais acionadas nas práticas discursivas de coletivos e coletivas, utilizadas como fontes para fins deste artigo, são publicações de textos escritos e imagéticos nas mídias sociais Facebook e/ou Instagram desses agrupamentos. Como práticas discursivas, essas mídias “[i]mplicam ações, seleções, escolhas, linguagens, contextos, enfim, uma variedade de produções sociais das quais são expressão. Constituem, dessa forma, um caminho privilegiado para entender a produção de sentido no cotidiano" (Spink, 2013:21). As práticas discursivas são constituídas pela "dinâmica, ou seja, enunciados orientados por vozes; as formas, que são os speech genres [...]; e os conteúdos, que são os repertórios interpretativos" (Spink, 2013:26 - grifos no original). Chamadas correntemente de "redes sociais", tais práticas discursivas dão-se por meio de sistemas online de mídias sociais projetados para permitir a interação social que se traduz na construção de redes sociais, as quais, diferentemente das naturais, apresentam intencionalidade dos relacionamentos e objetivos comuns entre quem nelas interage.

Como tais fontes constituem documentos públicos, elas são aqui acionadas nos marcos do que estabelece a ética na pesquisa, sem feri-la. Assim, em junho de 2020, em uma atualização de pesquisa iniciada em junho de $2019^{5}$, realizamos um levantamento de agrupamentos atuantes na cidade de Teresina, por meio da busca de páginas cadastradas nas mídias sociais Facebook e Instagram que contém/continham o termo "coletivo" ou "coletiva" em seus títulos, descrições e/ou publicações. Encontramos 26 agrupamentos locais com tais mídias sociais próprias e um como parte de uma rede nacional ${ }^{6}$, totalizando 27 Coletivos/Coletivas. Vemos, assim, a abrangência do campo de ação nesses meios digitais, muitas vezes, na superação de limites da dependência de contingências espaço-temporais para atuação. O resultado dessa busca não esgota o universo das formas de mobilização na cidade,

\footnotetext{
${ }^{3}$ Do francês, "l'age de la textualité életronique". Sobre o debate, na literatura especializada, a respeito de limites e possibilidades das mobilizações para ação política por meio das redes sociais virtuais, ver Gajanigo e Souza (2014).

${ }^{4}$ O conceito de redes sociais, de Barnes (1987) a Castells (1999; 2000), tem larga utilização nas ciências sociais. E, diz Fialho (2015), ganha diferentes modos e sentidos, indo do metafórico (sociedade construída por redes de relações interpessoais ou intergrupais) ao analítico (análise de redes e conexões mapeadas e classificadas em termos der número, intensidade e qualidade dos nós).

5 O levantamento realizado em 2019 serviu de base para um artigo apresentado na IX Jornada Internacional de Políticas Públicas (Coimbra, 2019).

${ }^{6}$ Encontramos 26 páginas próprias de Coletivos e Coletivas atuantes em Teresina. Um dos Coletivos não possui página própria, sendo mencionado em uma página de âmbito nacional, com registros de formações em vários estados do Brasil, incluindo o Piauí e sua capital. Vide: https://www.instagram.com/naoenao_/
} 
onde reconhecemos a existência de agrupamentos não incluídos neste estudo, e cuja atuação não contempla o ambiente virtual, em especial, as plataformas referidas.

Cabe destacar que, dentre as páginas encontradas, optamos por registrar e analisar, inclusive, aquelas de coletivos/coletivas que já se dissolveram. Isso por considerarmos a dinâmica desse coletivismo em Teresina - e alhures - em que, dentre as caraterísticas, está a de certos grupos serem temporários, seja por decorrência de seus próprios objetivos, seja por outras circunstâncias. Ter esta fluidez em conta ajuda a melhor compreender o caráter sóciohistórico desta ação política em contextos empíricos. Com base no exposto, debruçamo-nos sobre a análise das práticas discursivas do conjunto das postagens de textos e imagens de cada coletivo/coletiva nas mídias sociais referidas.

\section{Coletivos: novas insurgências juvenis?}

A utilização do termo "coletivo" surgiu - no campo das artes - para designar agrupamentos de jovens artistas que desenvolviam trabalhos de forma coletiva, além de debaterem acerca de questões relacionadas ao circuito brasileiro de arte (Albuquerque, 2008). No Brasil, há registros de atividade de coletivos de artes nas décadas de 1970 e 1980, muito embora um hiato arrefecesse as formações, que só reacenderiam nos anos de 1990 (Rosas, 2006). Nessa década ocorreu a "expansão do papel do[a] artista dentro do circuito de arte" e, na dédaca seguinte, o evento Panorama da Arte Brasileira 2001 parece ter sido o pontapé para o "ressurgimento" dos coletivos (Albuquerque, 2008:77). Sant'Anna, Marcondes e Miranda, 2017:825) ressaltam a emergência de movimentos em cidades brasileiras imbuídos de "uma narrativa em que performances e instalações [...] vêm ganhando espaço dentro e fora das instituições como formas de atuação política, num crescente processo de artificação da esfera pública e politização da arte".

A postura crítica de artistas, as parcerias que passaram a estabelecer entre si, e as intervenções no espaço público urbano influenciaram o surgimento de outros grupos para referir a um modo específico de ação coletiva, baseada em características como: agrupamentos flexíveis e descentralizados, ênfase na troca de ideias, criações em parceria e realização de trabalhos em diálogo com os públicos ${ }^{7}$, por meio de produções que adentram diversos campos (arte, política etc.). Não demorou muito para que outros agrupamentos

7 O termo "público" refere-se à distinção socialmente estabelecida entre produção (artista) e fruição (público/plateia), como pontuam criticamente Bourdieu (2007); Débord; (2000); De Certeau (2012); Fleury (2009). Em muitos casos, coletivos provocam certas rupturas dessa fronteira, no sentido de promover um maior envolvimento dos "públicos" alçados ao papel de cocriação. 
absorvessem tanto o vocativo "coletivo" quanto as características que marcavam essas (novas) práticas. Foram surgindo, assim, coletivos "urbanos", "culturais", "educativos", "feministas" - para citar alguns.

Embora a nomenclatura "coletivo" não seja de uso recente, observa-se sua crescente utilização tanto em atribuição quanto em autodenominação, de modo a sugerir a presença de um "novo" formato de mobilização social. O tema insere-se na corrente de análise dos movimentos sociais, em especial, dos que se denominam "novos movimentos sociais", sobretudo por serem tidos como manifestações apartidárias e autônomas, marcadas pela horizontalidade, não institucionalidade e atuação em redes sociais virtuais (Perez; Souza, 2017; Lima, 2018). Para Perez e Silva Filho (2017:257), eles constituem "novas formas de mobilização da sociedade civil".

Ademais, como destaca Melucci (1997:12), movimentos juvenis constituem "redes de diferentes grupos, dispersos, fragmentados, imersos na vida diária [...], um laboratório no qual novos modelos culturais, formas de relacionamento, pontos de vista alternativos são testados e colocados em prática”. São redes que emergem, muitas vezes, de modo esporádico, visando a responder a problemas específicos, em uma mudança morfológica que força a redefinição das categorias analíticas de atores coletivos, sobretudo pelo fato de os conflitos expressarem-se em torno de recursos simbólicos em sociedades onde os meios pelos quais são criadas e distribuídas as possibilidades de identificação estão em contínua mudança. Assim, atores sociais vivem exigências contraditórias do sistema como fontes de conflitos, não permanentemente enraizados em uma categoria social única, durante a vida inteira. A própria natureza precária da juventude aponta para a questão do tempo, na sociedade, de modo que ela deixa de ser mera condição biológica, assumindo uma definição simbólica (Melucci, 1997).

O entendimento da dimensão simbólica, orientado pela perspectiva de construção social e cultural, revela tanto a pluralidade das juventudes quanto as concepções do ser jovem como um estilo de vida (Margulis; Urresti, 1996; Chmiel, 1996). De igual modo, para Pinto e Bonfim (2016), Trancoso e Oliveira (2014) e Mesquita et al (2016), a categoria juventudes, para além da faixa etária, vem sendo compreendida em sua heterogeneidade, pelas distintas formas como constroem suas histórias, seus gostos, desejos, modos de pensar, extrapolando tanto o termo juventude, no singular, quanto a sinonímia com determinada faixa etária.

A categoria, considerada em sua heterogeneidade - juventudes - constitui um conjunto social diversificado, abrangendo "[...] diferentes culturas juvenis em função de diferentes 
pertenças de classe, diferentes situações econômicas, diferentes parcelas de poder, diferentes interesses, diferentes oportunidades ocupacionais etc." (Pais, 1993:23). O tema juventude/juventudes é abordado por diferentes campos e correntes teóricas, como a sociologia, a antropologia e a psicologia social, cujos limites são muitas vezes fluidos, que contribuem para o entendimento do fenômeno como construção social ${ }^{8}$ para além da abordagem como categoria social, seja dando origem ao mito da juventude homogênea, seja apontando para sua diversidade (Pais, 1993). Além do mais, a temática é abordada em diversos ângulos (geracional, classista, culturas juvenis) (Doutor, 2016; Pais, 1990; 1993), indicando que tanto são muitas as juventudes quanto são heterogêneas as experiências, em termos materiais e simbólicos, de ser jovem a partir de pertencimentos - e interseccionalidades - de natureza étnico-raciais, territoriais, de classe social, de gênero, de culturas religiosas etc.

Vemos, então, que juventudes são, ao mesmo tempo, uma condição social e um tipo de representação (Dayrell, 2003) que não mais diz respeito apenas a uma determinada fase da vida, relacionada a uma faixa etária. Assim, pontua Sousa (2004:49), o grupo não pode ser caracterizado como homogêneo pelo fato de seus membros possuírem apenas a idade em comum, dado que "não se pode misturar juventude e os jovens; o primeiro [termo] é a fase, e o segundo são os sujeitos que vivem uma diversidade".

A atuação desta categoria na arena pública aponta para momentos paradigmáticos, no Brasil e no mundo, nos quais emergem sujeitos cada vez mais conscientes de seus pertencimentos interseccionais e de sua importância na construção de uma sociedade democrática e participativa. Ações culturais juvenis, portanto, "configuram-se como lócus privilegiado de ações políticas em que as dimensões estético-culturais tornam-se um indicador fundamental na compreensão de práticas políticas juvenis na contemporaneidade" (Borelli; Aboboreira, 2011:162).

Embora em tais práticas políticas juvenis a atuação presencial seja uma característica marcante de alguns coletivos, principalmente daqueles que propõem intervenções no espaço público e/ou que organizam, sobretudo, eventos culturais, a atuação no ambiente virtual é comum à grande maioria deles. No século XXI, com a sociedade em rede (Castells, 1999) e a democratização do uso da Internet, movimentos articularam-se em novos formatos e práticas,

\footnotetext{
${ }^{8}$ Sobre juventudes como categoria social, estudos latino-americanos apresentam três vertentes, não excludentes: "jovens como atores políticos", "jovens como problema social”; "jovens como cidadãos". As duas primeiras de teor "universalista" e a terceira de orientação "relativista". São noções não excludentes, embora tenham origens temporais diferentes (Vieira; Mayorga, 2019:108).
} 
de modo que a expansão e o fortalecimento de coletivos e o ativismo cultural associado ao ativismo virtual têm sido fenômenos representativos dos tempos atuais, como defendem Oliveira (2006), Mesquita (2008) e Paim $(2009)^{9}$, quando se referem a países da América Latina.

Na última década (2010-2019), as mídias digitais tornaram-se instrumentos de articulação de redes sociais de mobilizações políticas, envolvendo desde a publicação de textos até a marcação de eventos/manifestações, além da convocação de ativistas e da transmissão em tempo real desses acontecimentos (Queiroz, 2017). Para além dos computadores, os aparelhos de telefonia móvel, conhecidos pelo termo corrente celulares, são instrumentos que possibilitam o registro instantâneo de sons e imagens (fixas e em movimento) e que se transformaram em "arma de luta” (Augusto; Rosa; Resende, 2016:28) no campo do ativismo social, inclusive, em tempo real ${ }^{10}$.

No entanto, a apreensão da política pelo conhecimento científico não pode ser prisioneira do viés investigativo pelo qual a relação entre juventude e política é, na maioria das vezes, tratada como algo naturalmente existente, como uma "relação quase obrigatória" (Mayorga; Castro; Prado, 2012:261). Esta visão da relação possível entre juventudes e participação política de forma naturalizada encontra-se aprisionada entre dois extremos: a ideia de uma propensão "natural" para a política ${ }^{11}$ e a ideia de um distanciamento "natural" em relação à política. Investir na desnaturalização das ideias presentes nesta polarização exige indagar se e como o ativismo juvenil contemporâneo tem contribuído para a construção e constituição da esfera pública. Importa, ainda, problematizar quais concepções de política, sociedade e democracia estão subjacentes às análises desse ativismo, desnaturalizando, também, a própria concepção de participação política (Mayorga, 2013).

Na pesquisa da relação entre juventudes e política, o tema da "formação de coletivos expressa formas de passagem das ações individuais para as ações coletivas e suas articulações com outros atores [...] como sendo a constituição de identidades coletivas no âmbito das ações

\footnotetext{
${ }^{9}$ Sobre o uso da internet, articulando o espaço cibernético à dimensão presencial e vice-versa, em diferentes formas de utilização, ver Sousa (2014) ao referir-se à rede como mecanismo possibilitador da geração e do fortalecimento dos laços de companheirismo/militância, e que contribui para que ativistas se reconheçam como membros de uma comunidade ou de uma genealogia de movimentos.

${ }^{10}$ Vale mencionar que coletivos juvenis podem voltar-se a objetivos emancipatórios ou não, sobretudo, em tempos atuais, quando "hordas digitais" se colocam a serviço da disseminação do ódio, de populismos de extrema direita, na era da "política quântica" (Empoli, 2019).

${ }^{11}$ Esta ideia, em grande medida, deve-se ao fato de a sociedade atribuir às juventudes uma condição reificada acerca de uma natureza "questionadora", "rebelde", como "uma fonte importante de mudança e transformação social" (Abramo, 2005:26).
} 
coletivas [...] na constituição de um "nós"” (Mayorga, 2013:349). Enfatizamos, consoante Melucci (2004), que identidades se fundam nas próprias relações sociais, nas quais vivemos pertencimentos (étnicos, raciais, linguísticos, religiosos etc.) em suas interseccionalidades. É nesse âmbito que se dá a busca de si, no plano individual ou coletivo. No processo, buscamos desenvolver a capacidade de reconhecermos os efeitos da nossa própria ação e de reconhecêla como nossa, para além de tomá-la como simples reflexo de vínculos biológicos e ambientais.

Nessa perspectiva, identidades são produções simbólicas de sentidos pelas quais nos reconhecemos e vivemos experiências de convergências, divergências, consensos, conflitos etc, em nossa própria construção processual, em nossos pertencimentos a uma pluralidade de grupos e a múltiplos papéis sociais. Cada vez mais, e com maior rapidez, no âmbito de uma modernidade que se transforma, não somos mais um eu definido de uma vez, para sempre. Acionamos identidades múltiplas - e fluidas, como salienta Bauman (2005) -, entrando e saindo de grupos de pertencimentos, vivendo-as como "celebração móvel” (Hall, 1998:13). Esta concepção de identidade, não essencialista, teoriza sobre posições de sujeitos em movimento, como seres interpelados por múltiplos agenciamentos discursivos.

Nesse processo de construção identitária, a troca de experiências, informações e visões de mundo entre jovens da face planetária, em sua diversidade, põe em circularidade dilemas e perspectivas juvenis em uma sociedade globalizada na qual a propagação veloz de símbolos e valores permite que jovens, em sua multiplicidade geográfica, cultural e social, possam, de alguma forma, partilhar de universos comuns de preferência. Esta ação coletiva não se inicia mais - nem recai -, necessariamente, em pertencimentos de grupos institucionalizados (movimentos estudantis, alas jovens de partidos ou de igrejas) (Novaes, 2019).

Não se pode ignorar, no entanto, que o acionamento da nomenclatura "coletivo" vem avançando, mesmo em ambientes institucionalizados. De fato, não só a expansão do termo como o consequente modo de atuar politicamente podem ser observados em espaços institucionalizados de organização coletiva da ação política, a exemplo do acadêmico, como expressões de lutas diversas pela ampliação do exercício de participação social. Muitas vezes, até mesmo funcionando como dispositivo de pressão para ampliação da participação de representantes da sociedade civil e de grupos específicos em instâncias como conselhos gestores, conferências locais, regionais, nacionais, e outros espaços intergovernamentais.

Mas, como novas formas de organização e de ação política, os coletivos extrapolam essas instâncias, inclusive, pelo fato de que elas, muitas vezes, além de não suprirem as 
demandas de grupos específicos, são tidas como engessadas pela própria institucionalidade. Assim, Milani (2008) aponta que, embora a participação diversificada seja estimulada pelos próprios discursos de participação que circulam, inclusive, no campo das políticas públicas voltadas para juventudes, a participação nem sempre se dá de forma equitativa. Muitas vezes, a própria legitimidade do processo institucional participativo voltado à construção do interesse coletivo não é garantida, por não contemplar de forma efetiva a diversidade de identidades coletivas. Além do mais, como destaca Sousa (2014:64), o coletivismo juvenil traduz novos modos de organização da vida cotidiana, de negação institucional, do enfrentamento da ordem, nos quais "a matéria da política revela-se como uma luta contra a política como tecnologia e poder cada vez mais afastada da experiência emancipatória”.

\section{Coletivos e coletivas juvenis de Teresina (PI) em suas midias sociais}

Entre coletivos juvenis alhures, as mídias digitais constituem um fenômeno em que, "conectados globalmente, coletivos juvenis agem localmente a partir das especificidades de seus territórios" (Novaes, 2019, s/p). Em Teresina, as redes sociais Facebook e Instagram são bastantes utilizadas por agrupamentos juvenis para criação/divulgação de conteúdos, articulação de grupos de discussão, publicação de textos e imagens, e realização de transmissões online e registros de sua atuação em espaços físicos da cidade, razões pelas quais selecionamos essas mídias sociais como fontes. Os 27 coletivos/coletivas que identificamos no levantamento, suas autorreferidas identidades, pautas declaradas, campos de atuação e utilização das mídias sociais Facebook e Instagram estão apresentados no Quadro1.

Do total das 27 expressões do coletivismo juvenil, constatamos que 23 autodenominam-se "Coletivo" e quatro "Coletiva". O emprego desta nomenclatura apresentase na grande maioria dos agrupamentos, seja em sua autodenominação, seja em sua autodescrição. Isso sugere a adoção/difusão discursiva de um "novo" formato de mobilização social, como referido por Perez e Silva Filho (2017). Desse total, 20 utilizam o Facebook, 24 o Instagram e 17 ambas as mídias. Outro ponto observado diz respeito a movimentações mais expressivas na mídia social Instagram, principalmente no ano de 2020, com exceção dos agrupamentos com páginas apenas no Facebook. A presença no ciberespaço, como expressões da cultura digital (Lévy, 2009) desse coletivismo, tanto está relacionada à sua atuação em espaços físicos da cidade de Teresina quanto vai além, uma vez que não se trata apenas de 
divulgar ações realizadas nos espaços físicos da cidade, mas constituir uma forma virtual de atuação.

$\mathrm{Na}$ leitura e interpretação das práticas discursivas expressas nas publicações das páginas digitais dos 27 coletivos/coletivas, vimos que alguns agrupamentos informam sua data de surgimento e outros não e sete deles não apresentaram postagens no ano de 2020 ou no anterior. No entanto, esta ausência não é suficiente para afirmar que tais grupos não se encontrem ativos, uma vez que, nesse coletivismo, diversos fatores internos e externos redundam em flutuações na própria ação, de modo que a constatação da situação atual de cada agrupamento requer uma abordagem direta com representantes, o que foge aos limites desta pesquisa. Esse fenômeno relaciona-se, como afirma Melucci (1997; 2007), à natureza dispersa e fragmentária da vida cotidiana onde novos modelos culturais, como as próprias redes esporádicas, voltadas a problemas específicos, força a redefinição das categorias analíticas de atores coletivos, em meio a contínua mudança, sem enraizamentos definitivos, sobretudo, no que tange às juventudes. Nessa direção, chama a atenção tanto a variedade de coletivos/coletivas, com marcadores de identidades explícitos nas autodenominações, quanto a diversidade dos campos de atuação e de suas pautas.

Quadro 1 - Mapeamento de coletivos/coletivas em Teresina em suas mídias sociais: identidades coletivas, mídias, campos de atuação e pautas ${ }^{12}$

\begin{tabular}{|c|c|c|c|c|c|}
\hline \multirow[b]{2}{*}{$\mathbf{N}^{\mathbf{o}}$} & \multirow[b]{2}{*}{$\begin{array}{l}\text { Identidades coletivas } \\
\text { (autorreferência) }\end{array}$} & \multicolumn{3}{|c|}{ Mídias sociais } & \multirow{2}{*}{$\begin{array}{c}\text { Campos de atuação do/a } \\
\text { coletivo/coletiva } \\
\text { (pautas/repertórios de ação política) }\end{array}$} \\
\hline & & $\begin{array}{l}\text { Facebook } \\
\text { (1) }\end{array}$ & $\begin{array}{l}\text { Instagram } \\
\text { (2) }\end{array}$ & $(1+2)$ & \\
\hline 01 & Coletiva Batuque Feminista & - & $\mathrm{X}$ & - & Gênero, diversidade e feminismo \\
\hline 02 & Coletiva Enefar & $\mathrm{X}$ & - & - & $\begin{array}{l}\text { Universidade e direitos de estudantes; } \\
\text { Gênero, diversidade e feminismo }\end{array}$ \\
\hline 03 & Coletiva Lésbica Piauiense & - & $\mathrm{X}$ & - & Gênero, diversidade e feminismo \\
\hline 04 & $\begin{array}{l}\text { Coletivo Acadêmico de } \\
\text { Ciências Sociais }\end{array}$ & $\mathrm{X}$ & $\mathrm{X}$ & $\mathrm{X}$ & Universidade e direitos de estudantes \\
\hline 05 & [Coletivo] Acrobata & $\mathrm{X}$ & $\mathrm{X}$ & $\mathrm{X}$ & $\begin{array}{l}\text { Artes Visuais } \\
\text { Literatura } \\
\text { Cultura }\end{array}$ \\
\hline 06 & $\begin{array}{l}\text { Coletivo Enecos } \\
\text { Piauí/Aluir }^{13}\end{array}$ & $\mathrm{X}$ & $\mathrm{X}$ & $X$ & Universidade e direitos de estudantes \\
\hline 07 & Coletivo Antônia Flor & $\mathrm{X}$ & $\mathrm{X}$ & $\mathrm{X}$ & Direitos humanos \\
\hline
\end{tabular}

\footnotetext{
12 Reiteramos que a pesquisa foi realizada nos anos de 2019 e 2020 e que ocorreram mudanças ou mesmo a dissolução de alguns coletivos/coletivas, nesse intervalo. Assim, embora os termos "coletivo" ou "coletiva" possam não estar expressos no nome ou na descrição de certos agrupamentos, eles encontram-se nos conteúdos e/ou em legendas de suas postagens, em suas páginas virtuais. Por este motivo, nos agrupamentos que não utilizam "coletivo/coletiva" no próprio nome, estes termos aparecem entre colchetes, nos Quadros 1 e 2.

${ }^{13}$ Este coletivo apresenta-se como "Coletivo Enecos Piauí" no Facebook e como Coletivo Aluir - Enecos PI no Instagram.
} 


\begin{tabular}{|c|c|c|c|c|c|}
\hline 08 & Coletivo B R O Bró & $\mathrm{X}$ & $\mathrm{X}$ & $\mathrm{X}$ & $\begin{array}{l}\text { Arte: linguagens diversas } \\
\text { Gênero, diversidade e feminismo } \\
\text { Raça }\end{array}$ \\
\hline 09 & Coletivo CirCorisco & $\mathrm{X}$ & $\mathrm{X}$ & $X$ & Arte Circense; Cultura \\
\hline 10 & Coletivo Corpo Gordo Livre & - & $\mathrm{X}$ & - & Corpo \\
\hline 11 & $\begin{array}{l}\text { Coletivo de Doulas Ciranda } \\
\text { Semear }\end{array}$ & $\mathrm{X}$ & $\mathrm{X}$ & $\mathrm{X}$ & $\begin{array}{l}\text { Doulagem } \\
\text { Parto humanizado } \\
\text { Direitos Humanos } \\
\text { Feminismo } \\
\text { Corpo }\end{array}$ \\
\hline 12 & $\begin{array}{l}\text { Coletivo Feminista Classista } \\
\text { Ana Montenegro/Piauí }\end{array}$ & $\mathrm{X}$ & $\mathrm{X}$ & $\mathrm{X}$ & Gênero, diversidade e feminismo \\
\hline 13 & [Coletivo] In.surge & $\mathrm{X}$ & $\mathrm{X}$ & $X$ & $\begin{array}{l}\text { Lazer e entretenimento } \\
\text { Cultura } \\
\text { Transporte } \\
\text { Saúde } \\
\text { Educação }\end{array}$ \\
\hline 14 & [Coletivo] LabCine & $\mathrm{X}$ & $\mathrm{X}$ & $\mathrm{X}$ & Arte: Produção Audiovisual \\
\hline 15 & [Coletivo] Não é Não/Piauí & - & $\mathrm{X}$ & - & Gênero, diversidade e feminismo \\
\hline 16 & $\begin{array}{l}\text { Coletivo Negro Minervino } \\
\text { de Oliveira - Teresina }\end{array}$ & $\mathrm{X}$ & $\mathrm{X}$ & $X$ & $\begin{array}{l}\text { Raça } \\
\text { Direitos humanos }\end{array}$ \\
\hline 17 & $\begin{array}{l}\text { [Coletivo] } \\
\text { Ocuparte/OcupARTHE }\end{array}$ & $X$ & $\mathrm{X}$ & $X$ & $\begin{array}{l}\text { Arte } \\
\text { Defesa do patrimônio cultural da cidade } \\
\text { Direito à cidade e a seus espaços } \\
\text { públicos }\end{array}$ \\
\hline 18 & $\begin{array}{l}\text { Coletivo Piauhy Estúdio das } \\
\text { Artes }\end{array}$ & $\mathrm{X}$ & $\mathrm{X}$ & $\mathrm{X}$ & $\begin{array}{l}\text { Produção Audiovisual } \\
\text { Arte }\end{array}$ \\
\hline 19 & [Coletivo] Ruaz Crew & $\mathrm{X}$ & $\mathrm{X}$ & $\mathrm{X}$ & $\begin{array}{l}\text { Grafite } \\
\text { Artes Visuais }\end{array}$ \\
\hline 20 & [Coletivo] Salve Rainha & $\mathrm{X}$ & $\mathrm{X}$ & $\mathrm{X}$ & $\begin{array}{l}\text { Arte } \\
\text { Defesa do patrimônio cultural da cidade } \\
\text { Direito à cidade e a seus espaços } \\
\text { públicos }\end{array}$ \\
\hline 21 & Coletivo Teresina & - & $X$ & - & $\begin{array}{l}\text { Direito à cidade e a seus espaços } \\
\text { públicos }\end{array}$ \\
\hline 22 & Coletivo VDC & - & $\mathrm{X}$ & - & Arte - Produção Audiovisual \\
\hline 23 & Coletivo Viva o Centro & - & $\mathrm{X}$ & - & $\begin{array}{l}\text { Direito à cidade e a seus espaços } \\
\text { públicos Cultura } \\
\text { Arte } \\
\text { Defesa do patrimônio cultural da cidade }\end{array}$ \\
\hline 24 & $\begin{array}{l}\text { [Coletivo] Companhia de } \\
\text { Teatro Jovens em Cena } \\
\text { (COTJOC) }\end{array}$ & $\mathrm{X}$ & $\mathrm{X}$ & $\mathrm{X}$ & $\begin{array}{l}\text { Arte - Dramaturgia } \\
\text { Cultura }\end{array}$ \\
\hline 25 & FRITHE - Coletivo Urbano & $X$ & - & - & $\begin{array}{l}\text { Direito à cidade e a seus espaços } \\
\text { públicos }\end{array}$ \\
\hline 26 & Katias Coletivas & $\mathrm{X}$ & - & & Gênero, diversidade e feminismo \\
\hline 27 & Coletivo Mosh/ Mosh PI & $\mathrm{X}$ & $\mathrm{X}$ & $\mathrm{X}$ & Arte - Música \\
\hline \multicolumn{2}{|c|}{ Subtotais por mídia social } & 20 & 24 & 17 & - \\
\hline
\end{tabular}

Fonte: organizado pelas autoras, 2020.

Embora as temáticas de cada coletivo/coletiva não sejam estanques e, de fato, indiquem tanto diálogos entre pautas quanto a diversidade/especificidade das demandas, elas apontam, também, para identidades coletivas, no sentido referido por Mayorga (2013) e 
Novaes (2019). Sem reduzir identidades a nomes e às pautas declaradas, consideramos que estes elementos, juntamente com os repertórios de ação política, apontam para marcadores identitários coletivos significativos, nessa abordagem.

Considerando que as pautas identificadas nas práticas discursivas se relacionam estreitamente, e em recursividade, com os campos de atuação de cada um/uma dos/das coletivos/coletivas, essa observação permitiu-nos compreender que seria possível pensar em alguns campos comuns de atuação, em termos mais amplos. Assim, elaboramos - assumindo o que há de arbitrariedade nesse procedimento, como em qualquer classificação - uma organização dessas ações coletivas em campos de atuação compartilhados por vários agrupamentos, cujas pautas convergem. Esse recurso interpretativo permitiu-nos apresentar uma leitura sobre a convergência dos repertórios de ação política dos agrupamentos, além de indicar a fluidez dos limites tanto entre os campos quanto entre agrupamentos.

Desse modo, a categorização, com base nas práticas discursivas de coletivos/coletivas, resultou na identificação de cinco campos comuns de atuação (Quadro 2), nos quais se distribuem os 27 agrupamentos: 1) Universidade e direitos de estudantes; questões acadêmicas; questões sociais e políticas diversas 2) Clivagens sociais de gênero, diversidade e feminismo; 3) Direitos humanos, raça, corpo, parto e nascimento humanizado; 4) Direito à cidade e a seus espaços públicos e defesa do patrimônio cultural da cidade; e 5) Arte: linguagens artísticas e produtos culturais.

Quadro 2 - Coletivos/Coletivas por campos comuns de atuação

\begin{tabular}{|c|c|}
\hline $\begin{array}{l}\text { Campos comuns de atuação a vários } \\
\text { coletivos/coletivas }\end{array}$ & Coletivos/Coletivas por campo \\
\hline $\begin{array}{l}\text { 1) Universidade e direitos de estudantes; } \\
\text { questões acadêmicas; questões sociais e } \\
\text { políticas diversas }\end{array}$ & $\begin{array}{l}\text { 1. Coletiva Enefar } \\
\text { 2. Coletivo Acadêmico de Ciências Sociais Ciências } \\
\text { Sociais } \\
\text { 3. Coletivo Enecos Piauí/ Aluir }\end{array}$ \\
\hline $\begin{array}{l}\text { 2) Clivagens Sociais de gênero, diversidade e } \\
\text { feminismos }\end{array}$ & $\begin{array}{l}\text { 1. Coletiva Batuque Feminista } \\
\text { 2. Coletiva Lésbica Piauiense } \\
\text { 3. Coletivo Feminista Classista Ana Montenegro } \\
\text { (Piauí) } \\
\text { 4. [Coletivo] Não é Não (Piauí) } \\
\text { 5. Katias Coletivas }\end{array}$ \\
\hline $\begin{array}{l}\text { 3) Direitos humanos, raça, corpo, parto e } \\
\text { nascimento humanizado }\end{array}$ & $\begin{array}{l}\text { 1. Coletivo Antônia Flor } \\
\text { 2. Coletivo Corpo Gordo Livre } \\
\text { 3. Coletivo Negro Minervino de Oliveira - Teresina } \\
\text { 4. Coletivo de Doulas Ciranda Semear }\end{array}$ \\
\hline $\begin{array}{l}\text { 4) Direito à cidade e a seus espaços públicos e } \\
\text { defesa do patrimônio cultural da cidade }\end{array}$ & $\begin{array}{l}\text { 1. [Coletivo] In.surge } \\
\text { 2. Coletivo Teresina } \\
\text { 3. Coletivo Viva o Centro } \\
\text { 4. FRITHE - Coletivo Urbano } \\
\text { 5. [Coletivo] Ocuparte/OcupARTHE }\end{array}$ \\
\hline
\end{tabular}




\begin{tabular}{|l|l|}
\hline & 6. [Coletivo] Salve Rainha \\
\hline & 1. [Coletivo] Acrobata \\
& 2. Coletivo B R O Bró \\
& 3. Coletivo CirCorisco \\
& 4. [Coletivo] LabCine \\
5) Arte: linguagens artísticas e produtos & 5. Coletivo Piauhy Estúdio das Artes \\
culturais & 6. [Coletivo] Ruaz Crew \\
& 7. Coletivo VDC \\
& 8. [Coletivo] Companhia de Teatro Jovens em Cena \\
& (COTJOC) \\
& 9. Coletivo Mosh/ Mosh PI \\
\hline
\end{tabular}

Fonte: organizado pelas autoras, 2020.

A partir do exposto, buscamos refletir sobre como cada um dos agrupamentos definese nas mídias sociais e como elucida sua relação com a defesa das respectivas pautas, no âmbito dos campos de atuação. Iniciamos pelo campo "Universidade e direitos de estudantes; questões acadêmicas; questões sociais e políticas diversas", no qual identificamos três expressões de coletivismo juvenil comuns em ambientes para os quais convergem juventudes, a exemplo de universidades. A propósito, Lima (2018) destaca que, no Encontro Nacional Universitário de Diversidade Sexual (ENUDS) de 2003 - evento que, ao longo de suas edições, foi reunindo grupos organizados em torno das pautas gênero e sexualidade e suas implicações políticas -, emergiram categorias como "militante" (sujeitos que atuam politicamente em coletividade) e "ativista" (sujeitos com atuação política individual).

Quanto ao uso do termo "coletivo", a autora menciona que ele apareceu na nomenclatura dos grupos nas edições de 2009 e 2010 do ENUDS, utilizado para referir-se a uma "construção coletiva", "horizontal" e "não hierárquica" no diálogo de integrantes, mesmo permanecendo instâncias como coordenações e presidência. Na prática, o emprego do termo sofreu 'uma expansão, mais sob um desejo de 'vir a ser' do que por serem 'de fato' espaços em que decisões são tomadas "por todos[as]"” (Lima, 2018:27). Vemos aqui, em especial em espaços institucionais, a reiteração do emprego da nomenclatura coletivo/coletiva como expressão do "novo", real ou idealizado.

De fato, na pesquisa, constatamos o acionamento desse termo mesmo em ambientes institucionalizados, a exemplo de um Centro Acadêmico e de duas representações estaduais vinculadas às Executivas Nacionais de duas organizações estudantis na Universidade Federal do Piauí. A adesão à referida nomenclatura parece traduzir novas experiências de mobilizações juvenis no espaço acadêmico, de forma - suposta ou realmente - menos verticalizada do que se dava no modo tradicional de organização do movimento estudantil. No que tange às pautas, estas vão desde as mais vinculadas à vida universitária, direitos de 
estudantes e questões acadêmicas àquelas voltadas a temáticas e questões sociais e políticas diversas.

É o caso do Coletivo Acadêmico de Ciências Sociais (2020, online), denominado CACS-UFPI/The-Coletivo Acadêmico de Ciências Sociais, cujo objetivo, declarado em sua página no Facebook, é “Ocupar e Resistir o curso, mobilizando, integrando, informando e apoiando os[as] estudantes". Na postagem, o segundo verbo, também grafado com inicial maiúscula ("Resistir") leva a supor uma possível transgressão gramatical intencional com vistas a enfatizar sentidos e finalidades da ação. Quanto às representações locais de executivas nacionais, que contemplam estudantes de distintas instituições de ensino superior no Brasil, identificamos a Coletiva Enefar (2020, online), vinculada à Executiva Nacional de Estudantes de Farmácia (Enefar) e que se define, em sua página no Facebook, como "articulação de estudantes de farmácia da Universidade Federal do Piauí, que se propõem a disputa política revolucionário [sic!]”; e, ainda, o Coletivo Enecos Piauí (Aluir) (2020, online), vinculado à Executiva Nacional de Estudantes de Comunicação Social (Enecos), que se apresenta, em sua página no Facebook, como "coletivo piauiense da Executiva Nacional dos Estudantes de Comunicação Social (ENECOS), entidade mobilizadora e representativa dxs estudantes de Comunicação Social, em nível de graduação, das instituições de ensino do país”. Embora vinculados à executiva nacional, informam que "os coletivos locais têm suas próprias atividades, pautadas na realidade vivenciada em cada universidade, mas também seguem orientações nacionais".

Uma leitura das postagens em mídias sociais de coletivos/coletivas no espaço acadêmico revela que, embora a defesa de interesses e direitos de estudantes sejam expressamente declarados, não se pode considerar sua ação política como estritamente voltada para esta pauta. De fato, identificamos posicionamentos políticos a favor ou contra determinadas outras bandeiras, inclusive com promoções de debates e chamamentos para discussões/conversas e eventos promovidos por outras entidades, envolvendo temas diversos, de interesse mundial, nacional, regional e local.

Nessa direção, a Figura 1 reproduz uma postagem de 31 de agosto de 2019 no Instagram $^{14}$ do Coletivo Aluir - Enecos PI, com uma imagem fotográfica registrando uma reunião para a discussão do tema "Violência contra a Mulher: a estruturalização de um Estado homicida" (Coletivo Aluir - Enecos PI, 2019, online), cuja apresentação em letras maiúsculas

\footnotetext{
${ }^{14}$ Dados os limites deste artigo, em termos de extensão, não foi possível apresentar imagens de postagens de cada um dos 27 coletivos/coletivas. Assim, trazemos um exemplo de prática discursiva por campo de atuação, segundo a classificação apresentada no Quadro1.
} 
pressupõe a ênfase intencional dada ao tema, chamando a atenção de quem lê. Na postagem, o coletivo informa que a ação é referente ao Projeto Político do XL Encontro Nacional de Estudantes de Comunicação (ENECOM), ocorrido em Roraima, em 2019, do qual representantes do coletivo iriam participar. Anuncia, ainda, o próximo encontro do coletivo, voltado a debater a temática "violências simbólicas e o direito de (re)existir fora da heterocisnormatividade" (Coletivo Aluir - Enecos PI, 2019, online), além mencionar a presença do coletivo, em eventos na cidade, com vendas de lanches para arrecadar recursos monetários para que integrantes participassem do Enecom.

Figura 1 - Postagem do Coletivo Enecos Piauí/Aluir

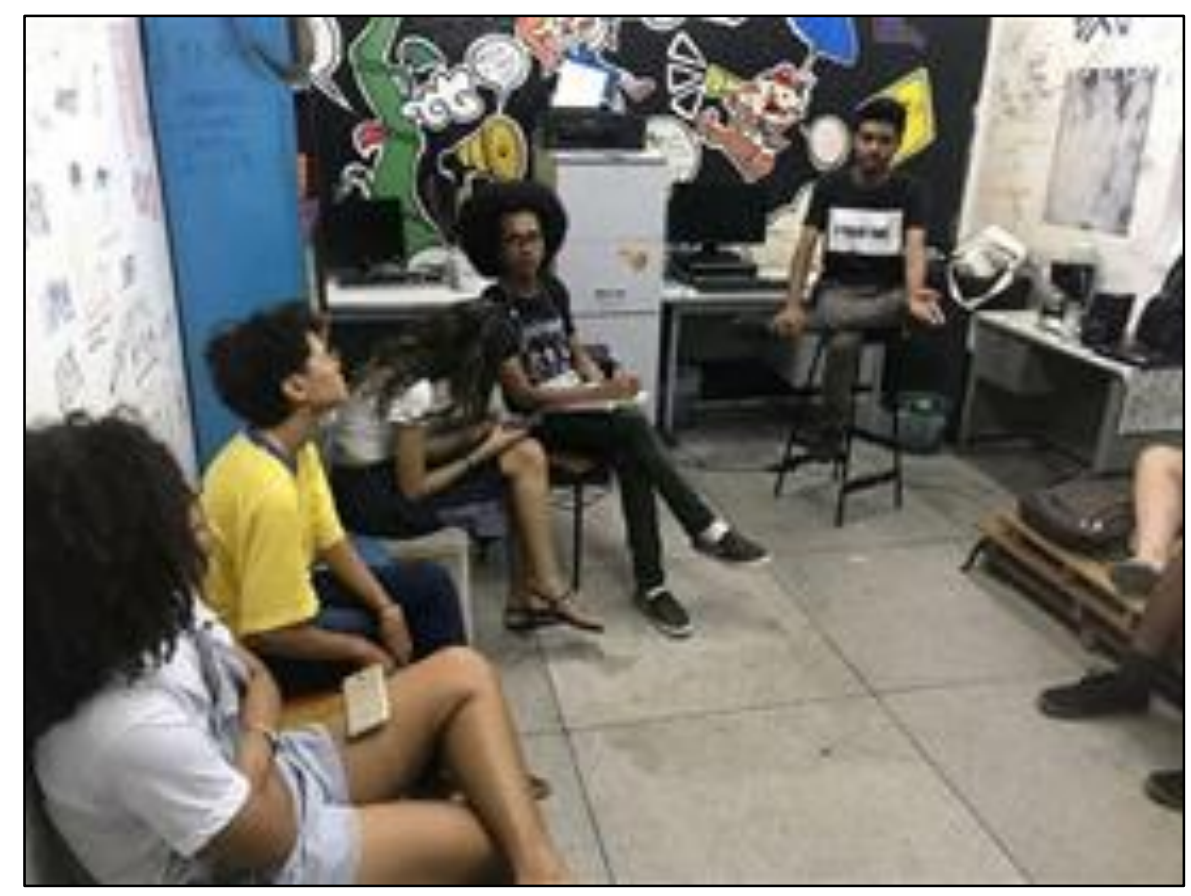

Fonte: https://www.instagram.com/p/B11vKgHj8hB/ (2019).

No que tange ao campo de atuação "Clivagens Sociais de gênero, diversidade e feminismos", encontramos cinco grupos. Três deles autointitulam-se "Coletiva", evidenciando a articulação política da linguagem, subvertendo hierarquias de gênero no próprio campo do coletivismo. Além da Coletiva Enefar, referida no Campo 1 (Quadro 2), as três coletivas do campo de atuação em pauta, são: a Katias Coletivas (2020, online), que se refere, em sua página no Facebook, como "coletiva de discussão e articulação de diversidade de gênero e sexual"; a Coletiva Lésbica Piauiense (2020a, online), que se apresenta, em seu Instagram, como "coletiva de mulheres lésbicas lutando por visibilidade"; e a Coletiva Batuque 
Feminista (2020, online), que se define, em seu Instagram, como "espaço de empoderamento feminino".

Além destas coletivas, identificamos mais dois coletivos deste campo, atuantes em Teresina, e vinculados a formações que levam o mesmo nome em diferentes estados: o Coletivo Feminista Classista Ana Montenegro/Piauí ${ }^{15}$ (2020), que se concebe como feministaclassista, com formações em mais de 15 estados brasileiros; e o Não é Não/Piauí ${ }^{16}$ (2020), que se identifica como grupo feminista de combate a assédios ao corpo feminino, também atuante em 15 estados brasileiros. Nos cinco coletivos/coletivas deste campo de atuação, vemos uma diversidade temática que aponta para a interseccionalidade de gênero, sexo e raça.

$\mathrm{Na}$ seleção de um exemplo, por campo de atuação, apresentamos, na Figura 2, uma reprodução de postagem no Intagram, de 29 de agosto de 2020 da Coletiva Lésbica Piauiense, sobre o Dia Nacional da Visibilidade Lésbica, referindo-o como "uma data que tem muita importância para nós, mulheres lésbicas, sapatonas, fanchas, entendidas, que lutamos diariamente para que nossas histórias não sejam apagadas, para que nossas relações e existências sejam validadas" (Coletiva Lésbica Piauiense, 2020b, online). Corroborando a importância dessa data, anunciam, na mesma postagem, que a criação da Coletiva foi idealizada após evento no Dia Nacional da Visibilidade Lésbica, em 2018.

Como ressaltado por Melo e Perez (2018) e Perez (2017), a atuação de Coletivos e Coletivas de gênero objetiva vocalizar a existência desses sujeitos, estar presente em espaços tidos como de relevância, ter suas diferenças reconhecidas e alcançar o atendimento a suas demandas. De fato, diz Perez (2017: 10), na atuação em defesa de marcadores sociais da diferença, como gênero, raça, orientação sexual e outros, de modo interseccional, "além de reproduzir tais discussões, os coletivos ajudam a divulgar e a construir uma certa compreensão a respeito das formas de opressão". As práticas discursivas no ambiente digital, nesse campo de atuação, em Teresina, parecem corroborar esta afirmação.

\footnotetext{
${ }^{15}$ Disponível em: http://anamontenegro.org/

${ }^{16}$ Disponível em:

https://benfeitoria.com/canal/naoenao?fbclid=IwAR25Sv9LGe92E65hKHY0jYQmtDEZEpJI01NvcaWlobEugsj -K5OtB4hvwag
} 
Figura 2 - Postagem da Coletiva Lésbica Piauiense

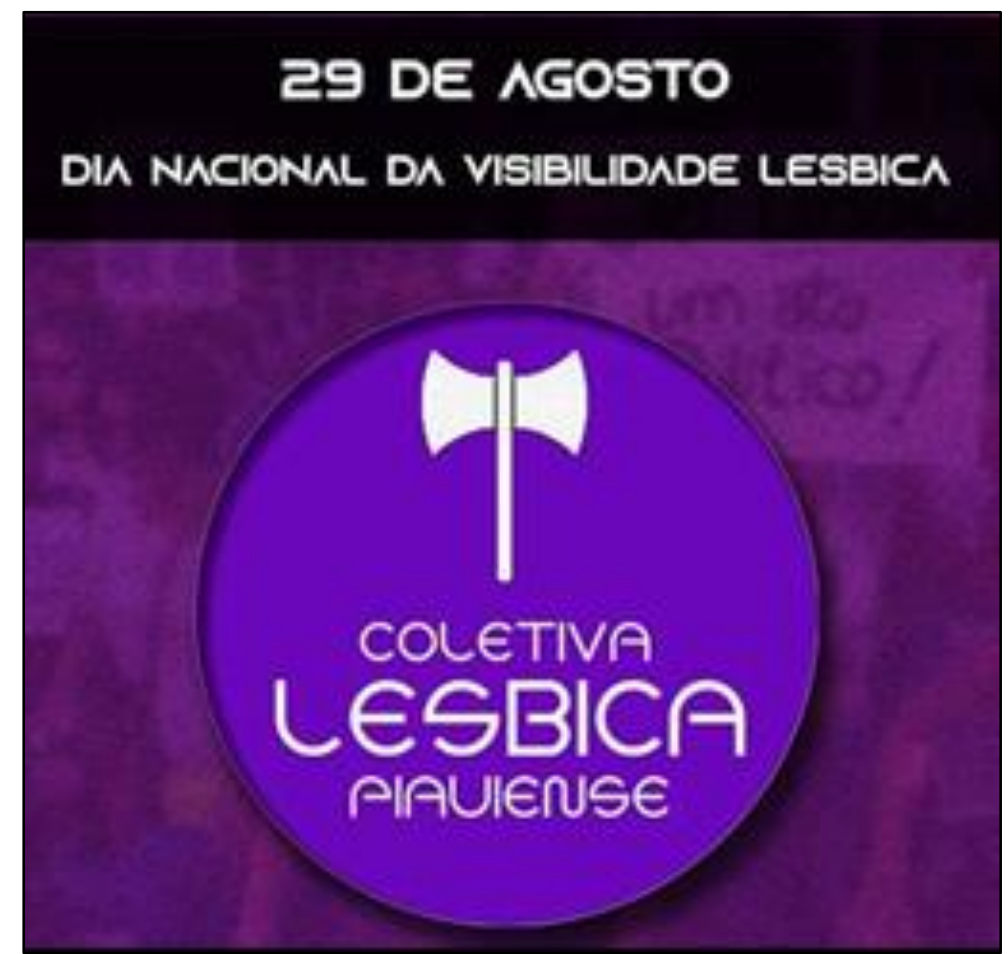

Fonte: https://www.instagram.com/p/CEekhbiDPak/ (2020).

No campo de atuação "Direitos humanos, raça, corpo, parto e nascimento humanizado", constatamos a presença de quatro agrupamentos: Coletivo Antônia Flor (2020), coletivo de direitos humanos; Coletivo Corpo Gordo Livre (2020, online), que se propõe, em seu Instagram, a "ressignificar um corpo desumanizado"; o Coletivo Negro Minervino de Oliveira/Piauí (2020, online), que se define, em sua página no Facebook, como "um coletivo do movimento negro, antirracista, anticapitalista, anti-imperialista, classista e parte integrante das lutas internacionalistas do proletariado", também com formações em outras cidades do Brasil; e o Coletivo Ciranda Semear (2020, online), que se autoidentifica, em sua página no Facebook, como "Coletivo de Doulas de Teresina que vem unir suas forças pela Humanização dos Partos e Nascimentos".

A diversidade temática nesse campo indica que as atuações de Coletivos se dão em diversas frentes, pautando a ressignificação de corpos desumanizados, sobretudo, pelo racismo estrutural, pelas hierarquias de gênero, pela ditadura de estéticas da moda e de certos discursos de áreas como medicina, educação física, nutrição, dentre outras. A temática do parto humanizado e o papel das doulas, por exemplo, é recorrente no Brasil, país com altas taxas de partos cesarianos, violências obstétricas e grande número de abortos clandestinos. Aqui, há diálogos com o campo "Clivagens Sociais de gênero, diversidade e feminismos”, em 
convergências com pautas feministas, sobretudo no que tange a direitos das mulheres sobre seus corpos e a legitimidade de suas escolhas com base na bandeira (defendida, também, por doulas) expressa no lema "Meu corpo, minhas regras" que, segundo Simas (2016:74), "evidencia o ideal de protagonismo das mulheres, seja para decidir sobre seus partos, seja para ter o direito a um aborto seguro caso necessário".

A luta contra o racismo, pautada por diversos coletivos e coletivas, na cidade, inclusive, localizados em outros campos, tem expressões próprias como na ação do Coletivo Negro Minervino de Oliveira, criado por militantes do Partido Comunista Brasileiro (PCB), em 2014, no Rio de Janeiro, com representações em vários estados brasileiros (Domingues, 2017). Para Domingues (2017:44), trata-se da revalorização de uma "memória negra comunista", que corresponde a uma “[...] narrativa típica da politização da memória". Em postagem no dia 24 de setembro de 2019 (Figura 3), em sua a página do Instagram, em Teresina, o coletivo apresenta Minervino de Oliveira como o primeiro homem negro candidato à Presidência do Brasil. Além disso, informa que o coletivo é contra qualquer tipo de exploração da classe trabalhadora, em específico da população negra (Coletivo Negro Minervino de Oliveira, 2019, online), apontando para a interseccionalidade raça/classe, como bandeira de luta contra o racismo e em defesa dos direitos da classe trabalhadora.

Figura 3 - Postagem do Coletivo Negro Minervino de Oliveira - Teresina, PI

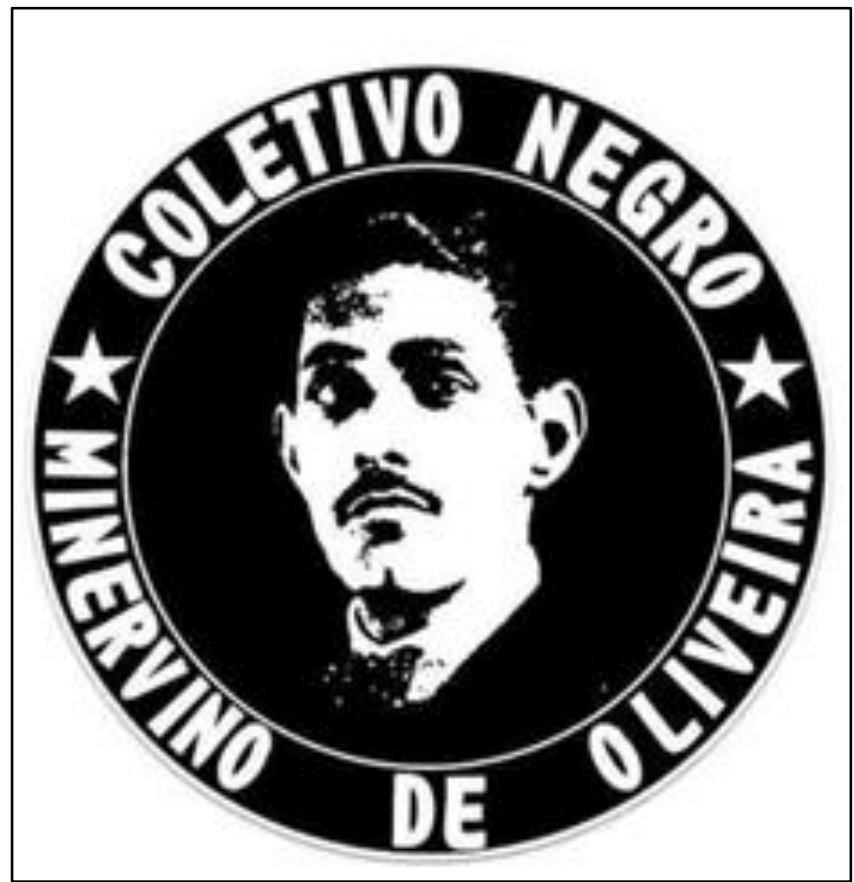

Fonte: https://www.instagram.com/p/B2yg5PDILlM/ (2019) 
A ampliação dos debates acerca do antirracismo, da identidade negra e das relações étnico-raciais, bem como do aumento da produção acadêmica a respeito de tais temas, traduz a ação de movimentos sociais antirracistas, no país. Isso equivale a dizer que "não há como pensar historicamente o antirracismo no Brasil sem considerar o papel fundamental que esses movimentos sociais têm tido ao longo das últimas décadas", ficando conhecidos pela nomenclatura de "Movimento Negro" (Trapp; Silva, 2010:90). O Coletivo Negro Minervino de Oliveira em Teresina é uma das expressões dessa mobilização política.

No campo de atuação "Direito à cidade e a seus espaços públicos e defesa do patrimônio cultural da cidade", as pautas dos seis Coletivos voltam-se, sobretudo, a temas relacionados à cidade de Teresina e a seus espaços públicos, inclusive, mobilizando pessoas a participar, nesses espaços, de eventos, debates e/ou intervenções e ocupações. Assim, ruas, praças, avenidas, prédios, muros e lugares tidos como "ociosos", dentre vários outros espaços, são ressignificados a partir da sua ocupação por coletivos.

Dentre eles, estão o Coletivo Teresina (2015), que, em publicação no Instagram, apresenta o objetivo de "discutir e compartilhar idéias que podem fazer o convívio social e a nossa cidade cada dia melhores; o Coletivo FRITHE (2020, online), que, em seu Facebook, declara voltar-se à “[...] abordagem dos problemas de Teresina e [à] procura de soluções através de intervenções e ações sociais"; o Coletivo Viva o Centro (2020, online), que se apresenta, em seu Instagram, como um "coletivo de jovens teresinenses com o intuito de dar visibilidade ao centro da cidade"; e o In.surge (2020, online), que se define, em seu Facebook, como "coletivo urbano de Teresina".

Dentre as diversas ações desses Coletivos, trazemos o exemplo do In.surge, que produziu um mapa colaborativo gratuito, destacando opções de lazer e de entretenimento em várias as zonas territoriais da cidade Teresina, a partir da vivência de jovens que o elaboraram, como ilustrado na Figura 4. Embora possa ser utilizado como guia turístico para visitantes, o mapa volta-se, sobretudo, para teresinenses, com vistas a que explorem a cidade e seus entretenimentos para além dos pontos de atração dispostos na chamada "área nobre"17.

\footnotetext{
${ }^{17}$ Expressão utilizada em contraponto a lugares periféricos dentro da produção do espaço urbano. São zonas de alto valor imobiliário, no caso de Teresina, correspondendo à sua zona Leste. Segundo Carlos (2009), essa lógica de produção do espaço segue a racionalidade técnica do capital industrial/financeiro, transformando o espaço em mercadoria, viabilizando a realização do ciclo do capital.
} 
Figura 4 - Parte do mapa colaborativo criado pelo In.surge ${ }^{18}$

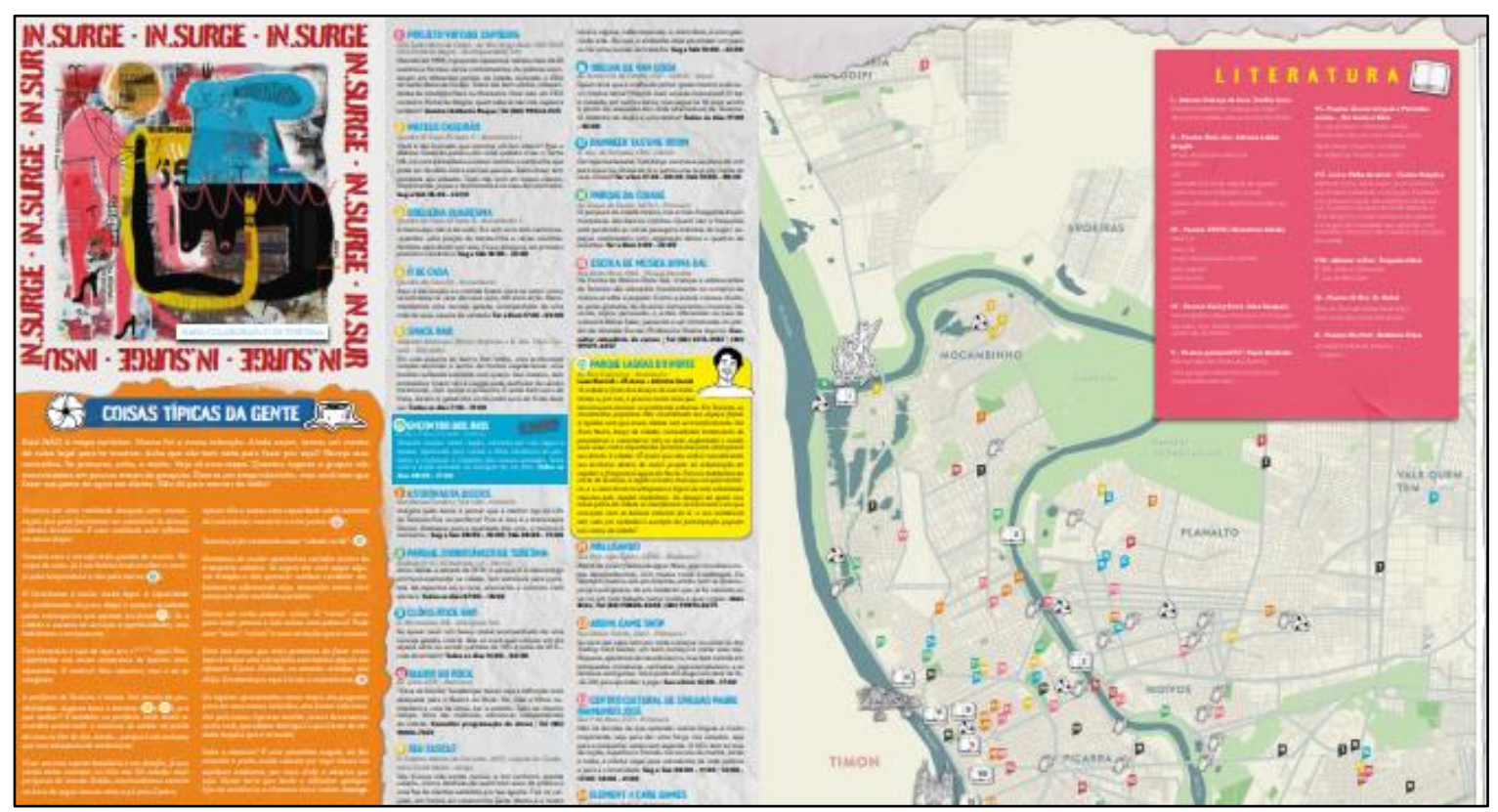

Fonte: https://www.facebook.com/theinsurge (2020).

Ainda dentre os coletivos que problematizam a cidade e os usos/desusos dos espaços públicos, encontramos, na pesquisa, dois coletivos que atuam por meio da arte: o Ocuparte/OcupARTHE e o Salve Rainha, os quais acionam diversas linguagens artísticas (música, artes cênicas, literatura, fotografia, cinema e vídeo, artes plásticas e visuais, artesanato), por meio de ações ou de eventos culturais, sempre focados no viver Teresina. $\mathrm{O}$ Ocuparte/OcupARTHE traz a seguinte descrição em sua página no Facebook: “arte, cidade, memória... a ocupação foi decretada!" (Ocuparte/OcupARTHE, 2020, online), em que "fica explícita a concepção da cidade como lugar de memórias, e proclama a arte como meio para as intervenções" (Coimbra, 2018:2757). Por vezes o coletivo se apresenta com o nome "OcupARTHE", que, inclusive, é a indicação da página virtual do Facebook (@OcupARTHE), fazendo uma referência à ocupação por meio da Arte e à ocupação em Teresina, que, localmente, é abreviada como “THE”. Já o Salve Rainha (2020, online) identifica-se, em sua página no Facebook, como "tecnologia Social de Valorização do Patrimônio Cultural de Teresina". Esteve atuante entre os anos de 2014 e 2018 e também ocupava espaços públicos na cidade, por meio de diversas ações e produtos/serviços culturais.

18 O mapa foi disponibilizado nos formatos físico e digital. O mapa completo, em formato digital, encontra-se na página do Facebook do coletivo:

https://drive.google.com/file/d/1HHS0OwgDZ3ukx1X_RKLzpsqcXwsrkGLM/view?fbclid=IwAR3yLsWOI3U YUG2HyNjfMSO2U-NqyPpBWFic9cLKYeWkLwrKS̄EnqQ65H-VM 
A autoidentificação destes dois coletivos revela o caráter de não-neutralidade da ação social de ocupação de lugares, com o intuito de lançar luz sobre esses como patrimônios culturais da cidade. Como tal, são tidos como "lugares de memória" nos termos de Le Goff (1990:13), para quem este conceito refere-se "[à] noção de duração, de tempo vivido, de tempos múltiplos e relativos, de tempos subjetivos ou simbólicos", em uma "ancoragem espacial", como dito por Halbwachs (1990:131), ao abordar a relação entre a "memória coletiva e o espaço". Esta relação com os lugares da cidade fundamenta a crítica às chamadas "revitalizações urbanísticas", que agridem a paisagem cultural (Monte; Moraes, 2016:262), e a provocação aos teresinenses a apropriarem-se dos espaços urbanos, tendo em conta o valor de uso da cidade, o sentidos de pertencimento, e a valorização dos patrimônios tangíveis e intangíveis.

Ademais, chama a atenção, ainda, a utilização do vocábulo "Teresina" ou mesmo de elementos referenciais à cultura local, caso das expressões "The" e "B R O Bró19" na nomenclatura e/ou descrição de alguns agrupamentos (Coletivo Teresina; Coletivo B R O Bro; Coletivo FRITHE; Coletivo OcupARTHE). São signos e símbolos acionados como marcadores identitários que enfatizam ancoragem na urbe. Como tal, constituem marcas acionadas em postagens sobre divulgação e realização de eventos; intervenções realizados e/ou referentes a espaços, sobretudo, tidos como sítios históricos da cidade.

Nessa direção, é comum que a ação de coletivos busque estimular a identificação de pessoas nativas com a própria cidade, sobretudo, ante "revitalizações" conduzidas sob a ótica do valor de troca e do turismo (Riscado, 2018). Além do mais, “[...] pessoas que compõem os coletivos incorporam o papel de agentes que produzem cultura local" e, nesse sentido, "isto converge com o que diz Rubim (2017) quando destaca a importância de quem cria, inventa, e inova no campo da cultura, sejam artistas, cientistas ou mestres e mestras do campo da cultura popular" (Coimbra, 2018:2759).

O campo de atuação "Arte: linguagens artísticas e produtos culturais ${ }^{20 "}$, com seus nove coletivos, dialoga estreitamente com o campo anterior - "Direito à cidade e a seus espaços públicos e defesa do patrimônio cultural da cidade”. O marcador principal para posicioná-lo em um campo diferente deve-se ao foco dos agrupamentos desse campo nas

\footnotetext{
${ }^{19} \mathrm{O}$ termo refere-se ao período mais quente do ano na região piauiense, dos meses de setembro a dezembro, cuja sílaba final "bro" é comum a tais meses.

${ }^{20}$ Bourdieu (2007) define produto cultural como pertencente ao capital cultural objetivado, isto é, um artefato físico e/ou um elemento simbólico capaz de transmitir um valor de troca e um valor de uso. Segundo Canclini (1997), os produtos culturais podem ser classificados em quatro dimensões: a) manifestações artísticas; b) circuito histórico-territorial; c) elementos midiáticos; e d) elementos informacionais.
} 
linguagens artísticas e produtos culturais. Uma das marcas dos coletivos desse campo é a criação de produtos culturais relacionados a linguagens artísticas específicas (o que não impede hibridações) os quais são disponibilizados gratuitamente, ou não. Outra marca é a defesa da arte independente, que pode ser visualizada na descrição de vários coletivos. Identificamos, assim, seis eixos relacionados às linguagens artísticas e produtos culturais, com os respectivos coletivos correspondentes:

i) produção audiovisual, com o Coletivo VDC (2020, online), criado por estudantes universitários(as) e que se declara "com o intuito de se ajudarem com produções audiovisuais"; o Coletivo Piauhy Estúdio das Artes (2020, online), que se define, em sua página no Facebook, como "uma plataforma cênica que objetiva o ensino, pesquisa e criação artística"; e o LabCine (2020a, online), que se apresenta, em sua página no Instagram, como um "selo de fomento a laboratórios e núcleos de produção audiovisual independente". Em link disposto na página do Instagram, é possível acessar a página do coletivo na plataforma digital de audiovisual Vimeo, com a seguinte autodescrição: “o coletivo hoje se constitui em sua maioria por estudantes, pesquisadores, professores, entusiastas, realizadores, produtores da capital e interior do Piauí e Maranhão" (LabCine (2020b, online);

ii) arte circense, com o Coletivo CirCorisco (2020, online), que se define, em sua página no Instagram, como um grupo de "animação, performances e mini oficinas" circenses;

iii) grafite, com o Ruaz Crew (2020), que se apresenta, em seu Facebook, como "coletivo de grafiteiros";

iv) dramaturgia, com a Companhia de Teatro Jovens em Cena (COTJOC) (2020), que, na descrição de sua página no Instagram, destaca os dizeres: "20 anos fazendo história" e "somos um coletivo";

v) literatura e artes visuais, com o Acrobata (2020, online), que se apresenta, em sua página no Facebook, como "coletivo de escritores[as] e produtores[as] culturais com o propósito de atuar realizando atividades e criando produtos independentes, estabelecendo pontes que possam conectar, reforçar e ampliar o cenário local”, surgido a partir das atividades do mesmo grupo na produção da Revista Acrobata: literatura audiovisual e outros desequilíbrios $^{21}$, lançada em 2013, em formato impresso e como produção independente; e

vi) música, com o Mosh PI (2020/online), que se apresenta, em sua página do Facebook, como "Coletivo Underground das bandas de metal de Teresina-Pi"

\footnotetext{
${ }^{21}$ Disponível em: https://revistaacrobata.com.br/
} 
A produção independente aparece, explicitamente, na autodescrição dos coletivos Labcine e Acrobata. Ainda neste campo, no âmbito da defesa de artistas locais independentes, está o Coletivo B R O Bró (2020, online), que, em sua página no Facebook, se declara como fruto da "necessidade de unir artistas independentes que produzem arte no Piauí". A reprodução da postagem no Instagram deste coletivo, de 18 de janeiro de 2019 (Figura 5), traz imagem fotográfica de membros do coletivo na escadaria do Museu do Piauí, acionado como símbolo. Nesta postagem (Coletivo B R O Bró, 2019, online), cuja legenda inicia com os dizeres "MANIFESTO: Coletivo B R O Bró. Por uma arte revolucionária e independente!", referem o objetivo de despertar "nos[as] artistas a força necessária para reviver a arte política", afirmando sonhar "com a arte como arma e instrumento de libertação da vida". Na conclusão do texto, dizem: "acreditamos que a arte tem uma função de transformação social. Só existimos enquanto artistas e produtores[as] de arte, na medida em que nos reconhecemos, mutuamente, em nossas identidades e diversidades".

Figura 5 - Postagem do Coletivo B R O Bró

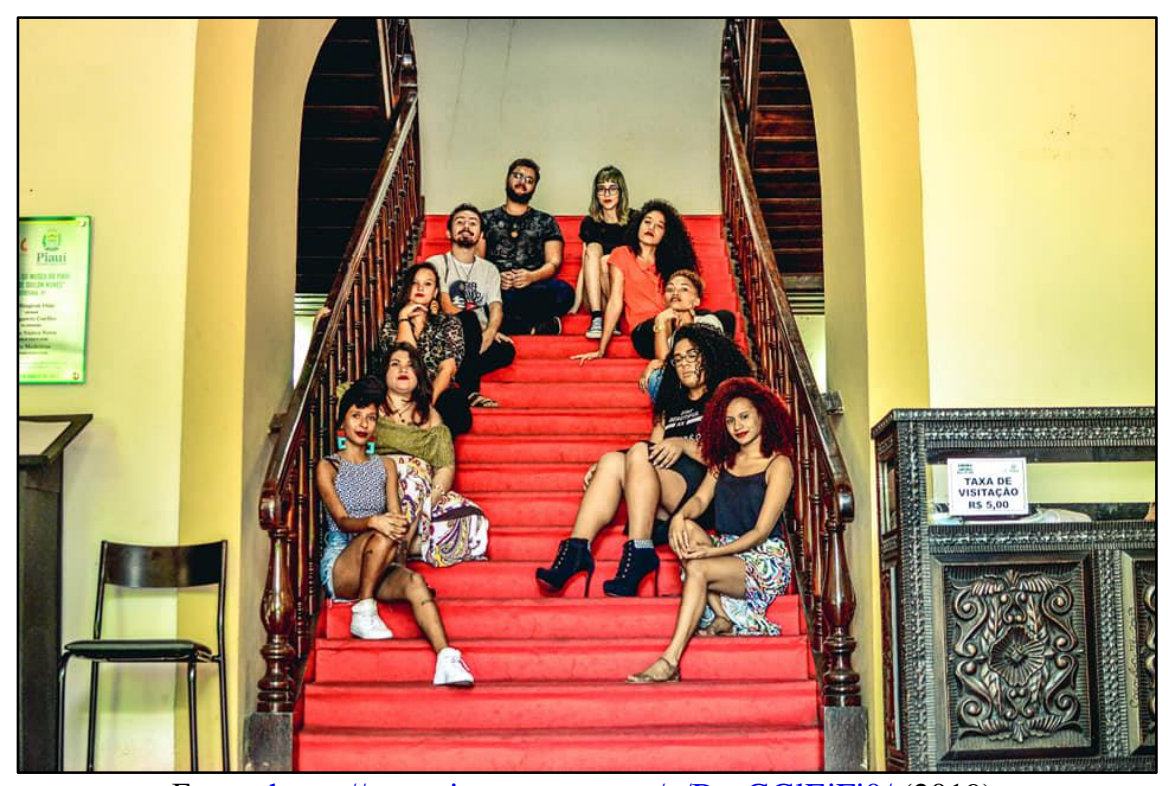

Fonte: https://www.instagram.com/p/BsyGGlEjFj0/ (2019).

Pelo exposto, vemos nas práticas discursivas expressas em textos escritos e imagéticos, nas mídias sociais analisadas, o largo uso do termo coletivo/coletiva como marcador identitário, corroborando a expansão da sua utilização e da adesão ao seu uso por parte do coletivismo juvenil, em Teresina. As práticas discursivas dos agrupamentos, suas pautas e objetivos, revelam que a ação política é elemento constituinte e fundamental dessa nova forma de mobilização intitulada coletivo/coletiva, concepção que se encontra, também, 
na literatura sobre o tema, inclusive com diálogos com a literatura sobre novos e novíssimos movimentos sociais (Perez; Silva Filho, 2017; Perez, 2017; Lima, 2018). Reiteramos, ainda, a circularidade de pautas entre coletivos/coletivas situados(as) em campos diferentes, o que mostra que os limites da classificação operacional que adotamos são fluidos.

Nesse sentido, em relação aos agrupamentos abordados nesta pesquisa, em sua maioria, a utilização da nomenclatura "coletivo" ou "coletiva" sugere sentidos não redutíveis a sinônimo de "grupo" ou a mero reflexo de um "modismo" decorrente da expansão da utilização de tais termos. Para além de uma denominação atribuída, exógena, denota a intencionalidade e a identidade política na autodenominação. Como salienta Gohn, (2016:4), atualmente, atualmente, observa-se uma preferência de jovens por organizar-se em coletivos em vez de movimentos sociais, estes, considerados como "[...] formas engessadas, tradicionais, estruturas centralizadoras. Os Coletivos, ao contrário, são vistos como agrupamentos fluidos, fragmentados, horizontais". No entanto, apontando para a dialética representações/práticas, a autora destaca que esta concepção juvenil de coletivos decorre "mais da narrativa que [estes] criam do que da realidade verificada". Além do mais, coletivos poderão, ou não, desenvolver práticas contestatórias, a depender do seu perfil e das estruturas relacionais entre jovens (Gohn, 2016).

Sem dúvida, a designação "coletivo", do ponto de vista teórico, pode ser atribuída tanto a movimentos voltados a objetivos emancipatórios quanto àqueles cuja ação direcionase à manutenção da ordem da dominação. No caso em apreço, os agrupamentos teresinenses pesquisados, que se autodenominam coletivo/coletiva, apontam para a característica de atuação em campos políticos de pautas emancipatórias, como indicam suas práticas discursivas seja por meio das pautas, seja por meio da construção/identificação de seus campos de atuação realizadas nesta pesquisa.

Chama a atenção, por exemplo, a própria flexão de gênero - "coletivas" - que, para além de mera atitude sexista, traduz perspectivas críticas às hierarquias de gênero e ao patriarcalismo, em interseção com demais pautas declaradas por coletivos e coletivas. No conjunto, são práticas discursivas que remetem a lutas emancipatórias e voltadas à ruptura de padrões sociais de dominação sustentados historicamente, no Brasil, por hierarquias de raça/etnia, gênero, classe social, sexualidade, direito, modelos corporais/estéticos, linguagens artísticas, usos da cidade, dentre outras, que se interseccionam na manutenção das estruturas de dominação. 
Embora alguns poucos agrupamentos não explicitem formalmente em suas mídias sociais os objetivos ou a descrição da finalidade de sua atuação, buscamos por indicialidades disto em suas postagens sobre a própria atuação. De fato, a maioria de coletivos e coletivas explicita nos textos escritos e imagéticos conteúdos que possibilitam identificar traços significativos de uma ação política contestatória e propositiva. Boa parte declara expressamente que suas constituições objetivam atuar na desconstrução de ordens sociais estabelecidas e/ou na defesa de direitos legalmente garantidos.

Como destacam Maia et al (2011:172), tais ações coletivas representam "uma tentativa de significação e possibilidade de mudança do que se apresenta enquanto realidade para esses indivíduos". Nesse sentido, “agrupamentos coletivos, movimentos sociais e políticos, constroem suas identidades enquanto grupos, a partir do contexto das relações de poder que os envolve". A forte presença de pautas em torno de marcadores sociais da diferença ressalta a politização da vida social como característica das formações que que se atribuem enquanto coletivo ou coletiva, seja na própria denominação, seja no conteúdo sobre suas atuações. Além da diversidade de pautas e campos de atuação, tais agrupamentos, em Teresina, utilizam-se de diversas metodologias de (inter)ação, principalmente pela presença expressiva de coletivos/coletivas de arte. Daí a expressão "ARTEvista", relacionada a alguns agrupamentos, como autorreferência a "ativistas culturais e políticos que lançam mãos das linguagens artísticas em suas proposições”, como pontua Leite (2018:12).

A interpretação do conjunto de postagens de coletivos/coletivas nas mídias sociais deixou evidente, ainda, que tais agrupamentos apresentam práticas discursivas nas quais aparecem como uma de suas principais ações a realização de intervenções e/ou eventos, seja nos espaços físicos da cidade (ruas, avenidas, praças, pontes, prédios públicos, universidades) ou no ciberespaço, por meio de lives, em suas próprias páginas, prática que se tem tornando comum neste momento, quando o mundo enfrenta a Pandemia de Covid-19. A realização de eventos/intervenções, assim como a interação virtual por meio de postagens e lives demonstra o foco na ação política, na arena pública. Essa dimensão pode ser vista como fundamental para os coletivos/coletivas, cuja ação se estabelece "com" e/ou "para" outrem, o que se imbrica na própria semântica das palavras "coletivo/coletiva". 


\section{Considerações finais}

Apresentamos neste trabalho um panorama da presença de coletivos/coletivas na cena urbana de Teresina, com foco em suas práticas discursivas nas mídias sociais Facebook e Instagram desses agrupamentos. Sem reduzir a expressividade das ações coletivas aos números, identificamos 27 expressões de coletivismo juvenil, sendo 23 grupos autodenominados Coletivos e quatro audenominadas Coletivas.

Constatamos que a diversidade de pautas - ou seja, dos repertórios de ação política de grupos específicos pode ser vista, no caso de Teresina, por diferentes ângulos. No que tange às identidades, destacam-se a própria e autodeclarada identificação como coletivo/coletiva, e a demarcação de identidades coletivas mais especificamente vinculadas a interseções socioculturais. Também chama a atenção a diversidade de coletivos/coletivas por campos de atuação, caso dos coletivos de arte; e, ainda, convergência de determinadas pautas por coletivos/coletivas situados(as) em campos diferentes, a exemplo dos campos "Direitos Humanos", "Gênero, diversidade e feminismo", "Direito à cidade e aos espaços públicos" e "Defesa do patrimônio cultural da cidade".

A partir da análise do panorama de coletivos/coletivas, em Teresina, foco deste estudo, constatamos que a maioria desses grupos compartilha algumas características, como: i) atuação no ciberespaço como componente substantiva e associada à atuação em espaços físicos da cidade, de modo que as redes digitais não são acionadas tão somente para divulgar ações, mas como um espaço específico de realização de ações; ii) a proposição da politização da vida social, inclusive com promoções de discussões sobre temas transversais a múltiplos campos da vida em sociedade, em ações voltadas para a coletividade, isto é, para participantes extra-grupos; iii) a centralidade da problematização do espaço urbano e (dos usos) do espaço público, tomando a cidade como lugar de memória, cujos patrimônios culturais (materiais e imateriais) devem ser valorizados; e iv) diferentes métodos de ação e de comunicação, mediados por múltiplas linguagens, como textos escritos e orais (em prosa e/ou versos), música, artes cênicas, literatura, fotografia, cinema, vídeo, artes plásticas e visuais, artesanato, dentre outras.

Algumas dessas expressões de coletivismo juvenil apresentam continuidade no tempo, outras ocorreram de forma efêmera. Algumas estruturam-se em uma divisão de atribuições e hierarquias, sobretudo aquelas presentes em espaços institucionais; outras são de caráter descentralizado e horizontal. Em sua maioria, utilizam-se de distintas abordagens na 
comunicação/ação, intervindo na dinâmica sociocultural de determinada(s) região(ões) da cidade. Temáticas e loci de atuação são intencionalmente escolhidos em função da política de ação dos agrupamentos. Ademais, reúnem-se em atuações que requerem a mobilização ampliada envolvendo vários grupos e linguagens.

O foco nas mídias sociais como práticas discursivas relacionadas à ação de coletivos/coletivas apontou elementos importantes à compreensão desse coletivismo, na cidade de Teresina. Sem dúvida, para além dos limites deste artigo, trazemos um conjunto de informações que podem alimentar outras pesquisas, por exemplo, a partir das vocalizações dos próprios sujeitos que atuam em coletivos e coletivas, o que permitiria explorar e aprofundar essa agência política, suas características, motivações, ações, estrutura organizacional, seus projetos, consensos e dissensos, etc. Ademais, pesquisas sobre como a sociedade civil e o Estado dialogam com esse coletivismo, na cidade, apontando para o tema do reconhecimento dessa ação, na arena pública.

\section{Referências}

ABRAMO, Helena, W. (2005), "O uso das noções de adolescência e juventude no contexto brasileiro", in M. V. Freitas (Org.). Juventude e adolescência no Brasil: referências conceituais. São Paulo, Ação Educativa, pp. 19-35.

ACROBATA (2020), Sobre. Facebook: Revistacrobata [Consult. 05-06-2020]. Disponível em https://www.facebook.com/pg/revistacrobata/about/?ref=page_internal.

ALBUQUERQUE, Fernanda (2008), "A atitude dos coletivos". Revista Porto Arte, Porto Alegre, v. 14, n. 24, pp. 75-82 [Consult. 20-05-2020]. Disponível em https://doi.org/10.22456/21798001.27937

AUGUSTO, Acácio; ROSA, Pablo. O.; RESENDE, Paulo E. R. (2016), "Capturas e resistências nas democracias liberais: uma mirada sobre a participação dos jovens nos novíssimos movimentos sociais". Estudos de Sociologia, v. 21, n. 40, pp. 21-37 [Consult. 18-05-2020]. Disponível em https://periodicos.fclar.unesp.br/estudos/article/view/7581

BARNES, John A. (1987), "Redes Sociais e Processo Político", In: B. Feldman-Bianco (org.). Antropologia das Sociedades Contemporâneas. São Paulo: Global, pp. 153-193.

BAUMAN, Zygmunt (2005), Identidade. Entrevista a Benedetto Vecchi. Rio de Janeiro: Jorge Zahar Ed.

BORELLI, Silvia H. S.; ABOBOREIRA, Ariane (2011), "Teorias/metodologias: trajetos de investigação com coletivos juvenis em São Paulo/Brasil". Revista Latinoamericana de Ciencias Sociales, Niñez y Juventud, v. 9, n. 1, pp. 161 - 172 [Consult. 28-05-2020]. Disponível em http://www.scielo.org.co/pdf/rlcs/v9n1/v9n1a09.pdf

BOURDIEU, Pierre (2007), A distinção: crítica social do julgamento. São Paulo: EDUSP. (1998), A economia das trocas simbólicas. São Paulo: Perspectiva. 
CANCLINI, Nestor G. (1997), Consumidores e Cidadãos. Rio de janeiro: UFRJ.

CARLOS, Ana F. A. (2009), A "ilusão" da transparência do espaço e a "fé cega" no planejamento urbano: os desafios de uma geografia urbana crítica. Cidades, Presidente Prudente, v. 6, n. 10, pp. 289-306.

CASTELLS, Manuel (1999), A sociedade em rede. São Paulo: Paz e Terra. (2000), A era da informação: economia, sociedade e cultura, v. 1, São Paulo: Paz e Terra.

CIRCORISCO (2020), Sobre. Instagram: circoriscothe [Consult. 05-06-2020]. Disponível em https://www.instagram.com/circoriscothe/

CHARTIER, Roger (2016), Chartier/Lecteurs et lectures à l'âge de la textualité électronique [Consult. 24-08-2020]. Disponível em http://encurtador.com.br/mqSV7

CHMIEL, Silvina (1996), "El milagro de la eterna juventude" in M. Margulis (ed.), La juventud es Más Que una Palabra. Buenos Aires, Biblos, pp. 85-101.

COIMBRA, Kary E. R. (2019), "Coletivos juvenis em Teresina”, in Jornada Internacional de Políticas Públicas, 9, 2019, São Luís, Anais do... São Luís: UFMA, Programa de Pós-Graduação em Políticas Públicas [Consult. 05-07-2020]. Disponível em http://www.joinpp.ufma.br/jornadas/joinpp2019/anais.html . (2018), "Arte e memória na ação cultural de coletivos teresinenses", in Congresso Internacional em Sociais e Humanidades, 7, 2018, Rio de Janeiro. Anais do... Rio de Janeiro: ANINTER-SH, pp. 2754-2763.

(2020), Coletivos juvenis em Teresina: pedagogias decoloniais interpelando políticas municipais de cultura. 2020. Projeto de Pesquisa (Doutorado em Políticas Públicas. Universidade Federal do Piauí, Teresina, 57 p.

COLETIVA BATUQUE FEMINISTA (2020), Página inicial. Instagram: batuquefeminista [Consult. 05-06-2020]. Disponível em https://www.instagram.com/batuquefeminista/

COLETIVA ENEFAR UFPI (2020), Sobre. Facebook: coletivaenefarufpi [Consult. 05-06-2020]. Disponível em https://www.facebook.com/pg/coletivaenefarufpi/about/?ref=page_internal

COLETIVA LÉSBICA PIAUIENSE (2020a), Página inicial. Instagram: coletivalesbicapi [Consult. 05-06-2020]. Disponível em https://www.instagram.com/coletivalesbicapi/

COLETIVA LÉSBICA PIAUIENSE (2020b), Postagem. Instagram: coletivalesbicapi [Consult. 2908-2020]. Disponível em https://www.instagram.com/p/CEekhbiDPak

COLETIVO ACADÊMICO DE CIÊNCIAS SOCIAIS (2020), Sobre. Facebook: CACS-UFPI/TheColetivo Acadêmico de Ciências Sociais [Consult. 04-06-2020]. Disponível em https://www.facebook.com/pg/CACS-UFPIThe-Coletivo-Acad\%C3\%AAmico-deCi\%C3\%AAncias-Sociais-812690742118553/about/?ref=page_internal

COLETIVO ALUIR - ENECOS PI (2019), Postagem. Instagram: coletivoaluir [Consult. 04-06-2020]. Disponível em https://www.instagram.com/p/B11vKgHj8hB

COLETIVO ANTÔNIA FLOR (2020), Sobre. Facebook: coletivoantoniaflor [Consult. 05-06-2020] Disponível em https://www.facebook.com/pg/coletivoantoniaflor/about/?ref=page_internal

COLETIVO B R O BRÓ (2020), Sobre. Facebook: coletivobrobropiaui [Consult. 06-06-2020]. Disponível em https://www.facebook.com/pg/coletivobrobropiaui/about/?ref=page_internal 
COLETIVO B R O BRÓ (2019), Postagem. Instagram:coletivobrobro [Consult. 06-06-2020]. Disponível em https://www.instagram.com/p/BsyGGlEjFj0/

COLETIVO CIRANDA SEMEAR (2020), Sobre. Facebook: coletivocirandasemear [Consult. 06-062020].

Disponível em https://www.facebook.com/pg/coletivocirandasemear/about/?ref=page_internal

COLETIVO CORPO GORDO LIVRE (2020), Página inicial. Instagram: corpogordolivreof [Consult. 05-06-2020]. Disponível em https://www.instagram.com/corpogordolivreof/

COLETIVO ENECOS PIAUÍ (2020), Sobre. Facebook: enecospiaui [Consult. 04-06-2020]. Disponível em https://www.facebook.com/pg/enecospiaui/about/?ref=page_internal

COLETIVO FRITHE (2020), Sobre. Facebook: frithe [Consult. 06-06-2020]. Disponível em https://www.facebook.com/pg/frithe/about/?ref=page_internal

COLETIVO NEGRO MINERVINO DE OLIVEIRA - TERESINA (2020), Sobre. Facebook: @ MinervinoPiaui [Consult. 06-06-2020]. Disponível em https://www.facebook.com/pg/ColetivoNegro-Minervino-de-Oliveira-Teresina-324154268256815/about/?ref=page_internal

COLETIVO NEGRO MINERVINO DE OLIVEIRA - TERESINA (2019), Postagem. Instagram: menervino.pi [Consult. 06-06-2020]. Disponível em https://www.instagram.com/p/B2yg5PDlLIM

COLETIVO TERESINA (2015), Postagem. Instagram: coletivothe [Consult. 06-06-2020]. Disponível em https://www.instagram.com/p/4RXBg3uQ-p/

COLETIVO VDC (2018), Postagem. Instagram: coletivovdc [Consult. 05-05-2020]. Disponível em https://www.instagram.com/p/BmQ2p1tjd7m/

COLETIVO VIVA O CENTRO (2020), Página inicial. Instagram: vivaocentrothe [Consult. 06-062020]. Disponível em https://www.instagram.com/vivaocentrothe/

COMPANHIA DE TEATRO JOVENS EM CENA (2020), Página inicial. Instagram: coletivo_cotjoc. [Consult. 05-06-2020]. Disponível em https://www.instagram.com/coletivo_cotjoc/

DAYRELL, Juarez (2003), “O jovem como sujeito social”. Revista Brasileira de Educação, n. 24, pp 40-52 [Consult. 23-05-2020]. Disponível em https://www.scielo.br/pdf/rbedu/n24/n24a04.pdf

DE CERTEAU, Michel (2012), A cultura no plural. Campinas, Papirus.

DÉBORD, Guy (2000), Sociedade do espetáculo. Rio de Janeiro, Contraponto.

DOMINGUES, Petrônio (2017), "Minervino de Oliveira: um negro comunista disputa a presidência do Brasil". Lua Nova, n. 101, pp. 13-51 [Consult. 10-06-2020]. Disponível em https://www.scielo.br/pdf/ln/n101/1807-0175-ln-101-00013.pdf

DOUTOR, Catarina (2016), "Um olhar sociológico sobre os conceitos de juventude e de práticas culturais: perspetivas e reflexões”. Última Década, Santiago, v. 24. n. 45, pp. 159-174 [Consult. 22-05-2020]. Disponível em https://scielo.conicyt.cl/pdf/udecada/v24n45/art09.pdf

ECKERT, Cornelia; ROCHA, Ana L. C. (2006), "Escrituras hipermidiáticas e as metamorfoses da escrita etnográfica no banco de imagens e efeitos visuais". Iluminuras, v. 7, n. 16, pp. 01-27 [Consult. 19-05-2020]. Disponível em https://seer.ufrgs.br/iluminuras/article/view/9254 
EMPOLI, Giuliano Da (2019). Os engenheiros do caos. Como as fake news, as teorias da conspiração $e$ os algoritmos estão sendo utilizados para disseminar ódio, medo e influenciar eleições. São Paulo: Vestígio.

FIALHO, Joaquim (2015), "Pressupostos para a construção de uma sociologia das redes sociais". Sociologia, v. 29, pp. 59-79 [Consult. 16-05-2020]. Disponível em http://ojs.letras.up.pt/index.php/Sociologia/article/view/1297

FLEURY, Laurent (2009), Sociologia da cultura e das práticas culturais. São Paulo: Editora Senac.

GAJANIGO, Paulo R.; SOUZA, Rogério F. (2014), "Manifestações sociais e novas mídias: a construção de uma cultura contra-hegemônica". Caderno CRH, Salvador, v. 27 n. 72, pp. 577-592 [Consult. 26-05-2020]. Disponível em https://www.scielo.br/pdf/ccrh/v27n72/09.pdf

GOHN, Maria da G. M. (2016), "Movimentos Sociais e Movimentos de Coletivos em São Paulo: o papel da política, dos mediadores e da media nas mobilizações, manifestações e protestos nas ruas na atualidade", in Encontro Associação Brasileira de Ciência Política, 10, 2016, Belo Horizonte, Anais [...]. Belo Horizonte: ABPC [Consult. 15-07-2020].

Disponível em https://cienciapolitica.org.br/eventos/10o-encontro-abcp/anais?page=23

HALBWACHS, Maurice (1990), A memória coletiva. São Paul, Vértice.

HALL, Stuart (1998), A identidade cultural na pós-modernidade. Rio de Janeiro, DP\&A.

INSURGE (2020), Sobre. Facebook: theinsurge [Consult. 04-06-2020]. Disponível em https://www.facebook.com/pg/theinsurge/about/?ref=page_internal

KATIAS COLETIVAS (2020), Sobre. Facebook: katiascoletivas [Consult. 05-06-2020]. Disponível em https://www.facebook.com/pg/katiascoletivas/about/?ref=page_internal

LABCINE (2020a), Página inicial. Instagram: labcine [Consult. 04-06-2020]. Disponível em https://www.instagram.com/labcine/

LABCINE (2020b), Página inicial. Vimeo [Consult.10-09-2020]. Disponível em https://vimeo.com/labcine

LE GOFF, Jacques (1990), História e memória. Campinas: Editora da UNICAMP.

LEITE, Luciana de L. L. (2014), Ocupar é rexistir! Práticas artísticas como tática de resistência nas ocupações do coletivo OcupARTHE, em Teresina. Dissertação (Mestrado em Antropologia), Universidade Federal do Piauí, Teresina, 195 p.

LÉVY, Pierre (2009). Cibercultura. São Paulo, Editora 34.

LIMA, Stephanie (2018), “'Coletivo', 'ativista' e 'horizontal': uma análise de categorias em uso no movimento social contemporâneo". Teoria e Cultura, v. 13, n. 1, pp. 18-35 [Consult. 24-05-2020]. Disponível em https://periodicos.ufjf.br/index.php/TeoriaeCultura/article/view/12382

MAIA, Allan J. V.; CARVALHO, Chrisse F. de; SÁ JÚNIOR, Luiz F. C. de; NAVARRO, Marcelo; BAROUH, Raquel; MOREIRA, Renata; SAMPAIO, Sônia M. R. (2011), "Juventude e Política: observando a Ufba", in S. M. R. Sampaio, (org), Observatório da vida estudantil: primeiros estudos. Salvador: EDUFBA, pp. 169-186 [Consult. 19-07-2020]. Disponível em http://books.scielo.org/id/n656x/pdf/sampaio-9788523212117-10.pdf 
MARGULIS, Mario; URRESTI, Marcelo (1996), La juventud es más que una palabra. Buenos Aires: Biblos.

MAYORGA, Claudia (2013), "Pesquisar a juventude e sua relação com a política - notas metodológicas". Estudos de Psicologia, v. 18, n. 2, pp. 343-350 [Consult. 19-05-2020]. Disponível em https://www.scielo.br/pdf/epsic/v18n2/v18n2a21.pdf

MAYORGA, Claudia; CASTRO, Lucia R.; PRADO, Marco A. M. (eds.) (2012), Juventude e a experiência da política no contemporâneo. Rio de Janeiro, Contra Capa Editora.

MELO, Iara C.; PEREZ, Olívia C. (2018), "Coletivos de gênero em Teresina-PI: uma forma de participação das mulheres na sociedade atual”, in L. C. X. Luz.; O. Perez; R. Marinho (Orgs.), Juventudes, subjetividades e sociabilidades. Teresina: Edufpi, pp. 190-212 [Consult. 28-05-2020]. Disponível em https://www.clacso.org.ar/biblioteca_brasil/detalle.php?id_libro=1904

MELUCCI, Alberto (1997), "Juventude, tempo e movimentos sociais". Revista Brasileira de Educação, n. 5, pp. 05-14 [Consult. 21-05-2020].

Disponível em https://anped.org.br/sites/default/files/rbe/files/rbe_05_e_06.pdf

MELUCCI, Alberto (2005), Por uma sociologia reflexiva. Pesquisa qualitativa e cultura. Petrópolis, Vozes.

(2004), O jogo do eu: a mudança de si em uma sociedade global. São Leopoldo, Ed. da Unisinos.

(2007), "Juventude, tempo e movimentos sociais", in O. Fávero; M. P. Spósito; P. Carrano; R.

R. Novaes (Orgs.), Juventude e Contemporaneidade. Brasília: UNESCO, MEC, ANPEd, pp. 29-46.

MESQUITA, André L. (2008), Insurgências poéticas. Arte ativista e ação coletiva (1990-2000). Dissertação (Mestrado em História Social), DH- USP, São Paulo, 428 p.

MESQUITA, Marcos R.; BONFIM, Juliano; PADILHA, Erise; SILVA, Ana C. (2016), "Juventudes e participação: compreensão de política, valores e práticas sociais". Psicologia \& Sociedade, v. 28, n. 2, pp. 288-297 [Consult. 21-05-2020]. Disponível em https://www.scielo.br/pdf/psoc/v28n2/18070310-psoc-28-02-00288.pdf

MILANI, Carlos R. S. (2008), "O princípio da participação social na gestão de políticas públicas locais: uma análise de experiências latino-americanas e europeias". Revista de Administração Pública, Rio de Janeiro, v. 42, n. 3, pp. 551-579 [Consult. 29-05-2020]. Disponível em https://www.scielo.br/scielo.php?pid=S0034-76122008000300006\&script=sci_abstract\&tlng=pt

MONTAGNER, Miguel A.; MONTAGNER, Maria I. (2011), "A teoria geral dos campos de Pierre Bourdieu: uma leitura". Revista Tempus Actas de Saúde Coletiva, v. 5. n. 2, pp. 255-273 [Consult. 12-07-2020]. Disponível em https://core.ac.uk/download/pdf/33543725.pdf

MONTE, Catarina N C..; MORAES. Maria D. C. (2016), "Paisagem cultural em (re)construção: artesanato ceramista, direitos culturais no Poti Velho, Teresina-PI”. Revista FSA. v. 13, n. 4, pp. 262-291 [Consult. 19-07-2020].

Disponível em http://www4.unifsa.com.br/revista/index.php/fsa/article/view/1079

MOSH PI (2020), Postagem. Facebook: @oficialmoshpi [Consult. 06-06-2020]. Disponível em: https://www.facebook.com/oficialmoshpi/posts/105312217702565

NÃO É NÃO! (2020), Página inicial. Instagram: naoenao [Consult. 04-06-2020]. Disponível em: https://www.instagram.com/naoenao_/ 
NOVAES, Regina (2019), Conectados globalmente, coletivos juvenis agem na realidade de seus territórios. Entrevista especial com Regina Novaes [Consult. 08-08-2020]. Disponível em: www.ihu.unisinos.br/159-noticias/entrevistas/589351-conectados-globalmente-coletivos-juvenisagem-na-realidade-de-seus-territorios-entrevista-especial-com-regina-novaes

OCUPARTE (2020), Sobre. Facebook: OcupARTHE [Consult. 05-06-2020]. Disponível em: https://www.facebook.com/pg/OcupARTHE/about/?ref=page_internal

OLIVEIRA, Lucia M. B. (2006), Corpos indisciplinados. Ação cultural em tempos de biopolítica. Tese (Doutorado em Ciência da Informação) ECA - USP, São Paulo, 225 p.

PAIM, Claudia. T. (2009), Coletivos e iniciativas coletivas: modos de fazer na América Latina Contemporânea. Tese (Doutorado em Artes Visuais), PPGAV - IA/UFRGS, Porto Alegre, 294 p.

PAIS, José M. (1990), “A construção sociológica da juventude - alguns contributos". Análise Social, v. 25, pp. 139-165 [Consult. 23-05-2020].

Disponível em http://analisesocial.ics.ul.pt/documentos/1223033657F3sBS8rp1 Yj72MI3.pdf (1993), Culturas juvenis. Lisboa: INCM.

PEREZ, Olívia C. (2017), "Surgimento e atuação dos Coletivos que discutem clivagens sociais". in Encontro Internacional Participação, Democracia e Políticas Públicas, 3., 2017, Vitória, Anais do.... Vitória: UFES [Consult. 16-05-2020].

Disponível em

https://www.researchgate.net/publication/318099286_Surgimento_e_atuacao_dos_Coletivos_que_ discutem_clivagens_sociais

PEREZ, Olívia C.; SILVA FILHO, Alberto. L. A. (2017), "Coletivos: um balanço da literatura sobre as novas formas de mobilização da sociedade civil". Latitude, v. 11, n. 1. pp. 255-294 [Consult. 18.05-2020]. Disponível em https://www.seer.ufal.br/index.php/latitude/article/view/2812

PEREZ, Olívia C.; SOUZA, Bruno M. (2017), "Velhos, novos ou novíssimos movimentos sociais? As pautas e práticas dos coletivos" in Encontro da Anpocs, 41, 2017, Caxambu Anais do... Caxambú: ANPOCS [Consult. 22-05-2020]. Disponível em http://anpocs.com/index.php/encontros/papers/41encontro-anual-da-anpocs/gt-30/gt11-15/10696-velhos-novos-ou-novissimos-movimentos-sociaisas-pautas-e-praticas-dos-coletivos?path=41-encontro-anual-da-anpocs/gt-30/gt11-15

PIAUHY ESTÚDIO DAS ARTES (2020), Sobre. Facebook: coletivopiauhy [Consult. 04-06-2020]. Disponível em https://www.facebook.com/pg/coletivopiauhy/about/?ref=page_internal

PINTO, Edmara C.; BONFIM, Maria do C. A. (2016), "Vivências, sociabilidades e cultura juvenil em movimentos alternativos de Teresina-PI", in L. C. X Luz; S. J. H. C. Adad; V. Silva (orgs.), Juventudes rurais e urbanas: territórios, culturas, sociabilidades e identidades. Teresina, Edufpi, pp. 387-403.

POUPART, Jean; DESLAURIERS, Jean-Pierre; GROULX, Lionel-H; LAPERRIÈRRE, Anne; MAYER, Robert; PIRES, Álvaro P. (2008), A pesquisa qualitativa. Enfoques epistemológicos e metodológicos. Petrópolis, Vozes.

PURPER, Raquel (2015), “Ação artística de caráter político: intersecções possíveis entre realidade, real e teatralidade nas experiências do Coletivo Mapas e Hipertextos". Rascunhos Uberlândia, v. 2, n. 2, pp. 131-139 [Consult. 26-05-2020].

Disponível em http://www.seer.ufu.br/index.php/rascunhos/article/view/31261 
QUEIROZ, Eliani F. C. (2017), "Ciberativismo: a nova ferramenta dos movimentos sociais". Panorama, v. 7, n. 1, pp. 02-05 [Consult. 28-05-2020].

Disponível em http://seer.pucgoias.edu.br/index.php/panorama/article/view/5574

RISCADO, Julia E. (2018), "Patrimônio e cidade: uma análise sobre os centros históricos brasileiros em tempos de reestruturação urbana". Métis: história \& cultura, v. 17, n. 33, pp. 293-306 [Consult. 22-05-2020]. Disponível em http://www.ucs.br/etc/revistas/index.php/metis/article/view/6694

ROSAS, Ricado (2006), "Notas sobre o coletivismo artístico no Brasil”. Rua, Campinas, v. 12, pp. 27 35 [Consult. 21-05-2020].

Disponível em https://periodicos.sbu.unicamp.br/ojs/index.php/rua/article/view/8640786

RUAZ CREW (2020), Sobre. Facebook: Ruazcrew [Consult. 06-06-2020]. Disponível em https://www.facebook.com/pg/Ruazcrew/about/?ref=page_internal

RUBIM, Antonio. A. C. (2017), Agentes culturais: delimitações e contextos de atuação. Salvador: RUMBIM-UFBA.

SALVE RAINHA (2020), Sobre. Facebook: salverainhacafe [Consult. 05-06-2020]. Disponível em: https://www.facebook.com/pg/salverainhacafe/about/?ref=page_internal

SANT'ANNA, Sabrina M. P.; MARCONDES, Guilherme; MIRANDA, Ana C. F. A. (2017), "Arte e política: a consolidação da arte como agente na esfera pública". Sociologia \& Antropologia, v. 7, n. 3, p. 825-849 [Consult. 03-06-2020].

Disponível em

https://www.scielo.br/scielo.php?script=sci_arttext\&pid=S2238-38752017000300825

SIMAS, Raquel (2016), Doulas e o movimento pela humanização do parto - poder, gênero e a retórica do controle das emoções. Dissertação (Mestrado em Antropologia), PPGA- UFF, Niterói, $142 \mathrm{p}$.

SOUSA, Carmem Z. V. (2004), "Juventude e contemporaneidade: possibilidades e limites". Última Década, v. 12, n. 20, p. 47-69 [Consult. 27-05-2020].

Disponível em

https://scielo.conicyt.cl/scielo.php?script=sci_arttext\&pid=S0718-22362004000100003

SOUSA, Janice T. P. de S. (2014), "A experiência contemporânea da política entre jovens no sul do Brasil. Buenos Aires, CLACSO [Consult. 13-08-2020].

Disponível em http://encurtador.com.br/bcxQ2

SPINK, Mary J. P. (org.) (2013), Práticas discursivas e produção de sentido no cotidiano. São Paulo, Cortez Editora.

TRANCOSO, Alcimar E. R.; OLIVEIRA, Adélia A. S. (2014), "Produção social, histórica e cultural do conceito de juventudes heterogêneas potencializa ações políticas". Psicologia \& Sociedade, v. 26, n. 1, pp. 137-147 [Consult. 19-05-2020]. Disponível em https://www.scielo.br/scielo.php?pid=S0102-71822014000100015\&script=sci_abstract\&tlng=pt

TRAPP, Rafael P.; SILVA, Mozart L. da S. (2010), "Movimento negro no brasil contemporâneo: estratégias identitárias e ação política". Revista Jovem Pesquisador, v. 1, pp. $89-98$ [Consult. 0206-2020].

Disponível em https://online.unisc.br/seer/index.php/jovenspesquisadores/article/view/2252 
VIEIRA, Bruno; MAYORGA, Cláudia (2019), "Juventude, ativismo político, políticas públicas e a confusão que é articular isso tudo". Revista Psicologia para América Latina, n. 32, pp. 107-117 [Consult. 38-05-2020].

Disponível em http://pepsic.bvsalud.org/pdf/psilat/n32/a03n32.pdf 


\begin{abstract}
The expansion of youth collectives in the city of Teresina, Piauí, throughout the decade of 2010, led us to question their presence in cyberspace through social media and about their political action agendas and areas of activity. Based on a survey on Facebook and Instagram, we identified 27 pages of Collectives, in which the written and image posts were taken, methodologically in a qualitative approach with an interpretive content, as discursive practices. As result, we found the selfdenomination "Collective" by almost all groups; the use of both social media or just one of them; the diversity of areas of activity/themes and their convergences; identity markers; and explicit or implicit objectives of performance-focused on social criticism, deconstruction/reconstruction of socio-cultural patterns and emancipatory projects.
\end{abstract}

Keywords: Collectives in Teresina; youth; discursive practices; social media.

\title{
Resumen
}

La expansión de los Colectivos/Colectivas juveniles en la ciudad de Teresina, Piauí, en los años 2010, nos llevó a indagar sobre su presencia en el ciberespacio a través de las redes sociales, y sobre sus líneas de actuación política y campos de actuación. A partir de una encuesta en las redes sociales Facebook e Instagram, identificamos 27 páginas de Colectivos/Colectivas, cuyas publicaciones de textos escritos e de imágenes tomamos, metodológicamente, en un enfoque cualitativo, con un contenido interpretativo, como prácticas discursivas. Como resultado, encontramos la autodenominación Colectivo/Colectiva por casi todos los grupos; el uso de ambas las redes o solo una de ellas; la diversidad de campos de acción/ lineamientos y sus convergencias; marcadores de identidad; y objetivos, explícitos o implícitos, de acción dirigidos a la crítica social, a deconstrucción/reconstrucción de patrones socioculturales y a proyectos emancipatorios.

Palabras clave: Colectivos y colectivas en Teresina; juventudes; prácticas discursivas; redes sociales. 